\title{
Avaliação de suscetibilidade à erosão e movimentação gravitacional de massa no Parque Estadual do Juquery, Franco da Rocha (SP)
}

\author{
Assessment of suscetibility to erosion and mass movements \\ in the Statepark of Juquery, Franco da Rocha, São Paulo State, Brazil
}

\author{
Danilo Gonçalves de Araújo Amorim¹, José Eduardo Zaine ${ }^{2}$, Danielle Bocarde ${ }^{3}$, Flávio Henrique Rodrigues ${ }^{1}$ \\ 'Pós-Graduação em Geociências e Meio Ambiente, Instituto de Geociências e Ciências Exatas, Universidade Estadual Paulista \\ "Júlio de Mesquita Filho" - UNESP, Rua Doutor Alfredo de Castro, 112, apto. 184, Barra Funda, CEP 01155-060, \\ São Paulo, SP, BR (danilo_gaa@yahoo.com; rodrigues.ambiental@gmail.com) \\ ${ }^{2}$ Departamento de Geologia Aplicada, Instituto de Geociências e Ciências Exatas, Universidade Estadual Paulista \\ "Júlio de Mesquita Filho" - UNESP, Rio Claro, SP, BR (jezaine@rc.unesp.br) \\ 3Unidade de Cartografia, Empresa Paulista de Planejamento Metropolitano S.A. - EMPLASA, São Paulo, SP, BR \\ (daniellebocarde@yahoo.com.br)
}

Recebido em 9 de dezembro de 2015; aceito em 19 de dezembro de 2016

\begin{abstract}
Resumo
A área de realização do estudo é o Parque Estadual do Juquery (PEJ), localizado no município de Franco da Rocha, Região Metropolitana de São Paulo, caracterizada por uma área de proteção de remanescente de cerrado. Essa unidade de conservação tem registrado problemas causados por processos de inundação, movimentos de massa e erosão hídrica. Baseado nesse histórico, este estudo teve como objetivo avaliar a suscetibilidade aos processos erosivos lineares (sulco, ravina e boçoroca) e de movimentos de massa, e fornecer subsídios ao planejamento e à gestão do meio físico da unidade. O mapeamento, realizado na escala de 1:20.000, subdividiu a área em 6 unidades geológico-geotécnicas, cujos resultados fomentaram a avaliação da suscetibilidade aos processos geológicos analisados. A avaliação de suscetibilidade considerou a possibilidade de ocorrência de processos morfodinâmicos em relação às características geológico-geotécnicas e foi realizada de forma qualitativa, adotando o método de análise gráfica, fundamentado na análise combinatória de variáveis de interesse. Para tanto, recorreu-se a técnicas de geoprocessamento, levantamentos de campo e análises gráficas. Como resultados, são apresentados os mapas de suscetibilidade aos processos erosivos e aos movimentos gravitacionais de massa. O mapa para processos erosivos aponta que $95 \%$ da área possuem moderada suscetibilidade e que 5\%, alta suscetibilidade; já para processos de movimentos de massa $88 \%$ possuem baixa suscetibilidade e $12 \%$, moderada suscetibilidade. Foram identificados dois pontos de interesse: uma boçoroca no extremo oeste e um trecho da estrada com ravinas. Conclui-se, portanto, que os processos erosivos representam o principal problema geológico-geotécnico do PEJ, visto que são decorrentes das características naturais do meio físico (geologia, geomorfologia e pedologia) e agravados pela ausência de cobertura vegetal e precariedade das estradas e trilhas.
\end{abstract}

Palavras-chave: Geologia de Engenharia; Cartografia Geotécnica; Avaliação de Suscetibilidade; Erosão Linear; Movimentos de Massa; Gestão Ambiental.

\section{Abstract}

The area of this study is the State Park of Juquery, located in the city of Franco da Rocha, Metropolitan Region of São Paulo, Brazil, characterized by a protected area of a remnant cerrado. This protected area has registered problems caused by flooding processes, mass movements and hydric erosion. Based on this framework, this study aims to evaluate the susceptibility to linear erosion and soil and rock slides, and support the planning and management of the physical environment of the that conservation unit. The mapping performed in the scale of 1:20.000 subdivided the area of study in six geological-geotechnical unit, whose results have fostered the evaluation of susceptibility to geological processes concerned. The susceptibility assessment analyzed the possibility of morpho- 
dynamic processes in relation to the geological and geotechnical characteristics and was carried out in a qualitative manner with application of graphical analysis method, which is based on the combinatory analysis of variables of interest. To this end, geoprocessing techniques, field surveys and graphical analysis were used. As a result, maps of susceptibility to erosion and landslide processes are presented. The erosion map shows that $95 \%$ of the park area has moderate susceptibility to the processes and $5 \%$ is considered high susceptibility. Concerning landslides, $88 \%$ has low sensitivity and $12 \%$ is considered moderate susceptibility. Two points of interest were identified, a gully at the west end, and a road with widespread ravines. It is concluded that linear erosion are the main geological-geotechnical problems of the State Park of Juquery, arising from natural characteristics of the physical environment and aggravated by the absence of vegetation cover and precariousness of roads and trails within the conservation unit.

Keywords: Engineering Geology; Geotechnical Cartography; Assessment of Susceptibility; Linear Erosion; Gravitational Mass Movements; Environmental Management.

\section{INTRODUÇÃO}

O Parque Estadual do Juquery (PEJ) está localizado no município de Franco da Rocha, na Região Metropolitana de São Paulo (Figura 1), e possui 1.956 ha. Trata-se de unidade de conservação de proteção integral com remanescentes do cerrado, onde são observados impactos ambientais decorrentes da antropização das áreas que o margeiam, devido à alta densidade populacional da região.

No limite oeste do PEJ estão localizados o Hospital Psiquiátrico do Juquery e a Linha 7 da Companhia Paulista de Trens Metropolitanos (CPTM), onde são comuns as interrupções na prestação de serviço devido a erosões, movimentos gravitacionais de massa, assoreamento, alagamento, enchente e inundação, principalmente nos períodos chuvosos (IPT, 2010).

Ao norte, localizam-se o complexo penitenciário da Polícia Militar e a Favela Pretória, uma área de ocupação irregular cuja população encontra-se socialmente vulnerável. Configurando-se como uma zona de tensão socioambiental, as tentativas de ocupação dos limites do parque são frequentes, bem como o conflito com pescadores e as fugas de detentos para o interior da unidade.

Também ao norte da área se localiza o Rio Juqueri, principal curso d'água da área de estudo, que recorrentemente sofre com processos de enchente e inundação, por diversos motivos, como assoreamento, canalização mal dimensionada, ocupação subnormal com lançamento irregular de efluentes, chuvas torrenciais, abertura de comporta da Represa Paiva Castro, entre outros.

Sendo assim, o presente estudo foi motivado pelo histórico reincidente de processos morfodinâmicos, os quais causam transtornos recorrentes à população, tanto pela inundação da área urbana e seu isolamento quanto pela interrupção do transporte público, bem como para fornecer subsídios para a elaboração do plano de manejo no parque.

Este artigo teve como objetivo avaliar a área do PEJ quanto à suscetibilidade aos processos erosivos e de movimentação gravitacional de massa.

\section{CONTEXTO GEOLÓGICO E GEOMORFOLÓGICO DA ÁREA DE ESTUDO}

\section{Geologia regional}

A área de estudo está inserida no contexto geotectônico da Província Estrutural da Mantiqueira, especificamente no Cinturão de Dobramento Ribeira, parte sul da Faixa Ribeira, sob o domínio São Roque, que é composto pelos Grupos São Roque e Itaberaba (Almeida et al., 1973; Cordani et al., 1973; Hasui e Oliveira, 1984; Heilbron et al., 2004; Campos Neto e Figueiredo, 1995). A litologia do Grupo São Roque corresponde, predominantemente, a filitos cinza esverdeados claros a escuros, que, quando alterados, apresentam coloração vermelha, castanha, alaranjada e rósea (Juliani et al., 1986).

Segundo Juliani e Beljavskis (1995), é comum estruturas bandadas ou laminadas, evidenciadas pela intercalação de camadas arenosas e micáceas, preservando feições sedimentares reliquiares, como

- estratificações rítmicas, cruzadas e gradacionais;

- marcas de onda;

- estromatólitos; sequência de Bouma e brechas.

De maneira isolada, podem ocorrer lentes de diversas dimensões compostas por metaconglomerados, quartzitos, metarcóseos, metagrauvacas, cálcio-xisto, calcários metamórficos e metabasitos (Juliani e Beljavskis, 1995).

O ambiente de deposição dos sedimentos do Grupo São Roque, proposto por Figueiredo et al. (1982), Hackspacher et al. (2000) e Juliani et al. (2000), aponta para uma bacia sedimentar do tipo retroarco.

O empilhamento estratigráfico e as nomenclaturas utilizadas para o Grupo São Roque possuem uma série de limitações (Juliani e Beljavskis, 1995). Quanto à subdivisão litológica em formações, suas nomenclaturas e o empilhamento são os seguintes: Formação Pirapora do Bom Jesus, sobreposta pela Formação Estrada dos Romeiros, a qual é coberta pela Formação Boturuna.

Quanto à geologia local, destaca-se a Formação Estrada dos Romeiros, composta predominantemente por metarritmitos, variando entre filitos e metassiltitos, e também 
metarenitos e metamicroconglomerado (Bergmann, 1988; Hackspacher et al., 1993; EMPLASA, 1979). A Figura 2 apresenta o mapa geológico regional com as principais estruturas geológicas, bem como a geologia do PEJ.

\section{Geologia estrutural}

O Grupo São Roque é constituído por sequência metavulcano-sedimentar de baixo grau metamórfico, metamorfisadas em fácies xisto verde, atingindo grau metamórfico mais elevado em pontos de intrusão de corpos graníticos (Juliani e Beljavskis, 1995). Em relação ao histórico de deformação do Grupo São Roque, Hackspacher et al. (1993) apontam a existência de, pelo menos, três eventos deformacionais, sendo as duas primeiras fases $(\mathrm{Dn}+1 \mathrm{e} \mathrm{Dn}+2)$ caracterizadas por dobras invertidas e recumbentes com foliação sub-horizontal associadas à Orogênese Brasiliana.

A terceira fase de deformação $(\mathrm{Dn}+3)$ caracteriza-se pelo tectonismo dúctil-rúptil, formando dobras normais de foliação vertical. O regime de evolução crustal é transtensivo no início e seguido de regimes transcorrentes/transpressivos (Hackspacher et al., 1993).

Juliani e Beljavskis (1995) descrevem a foliação S1 como uma foliação filítica a ardosiana finamente espaçada, já a
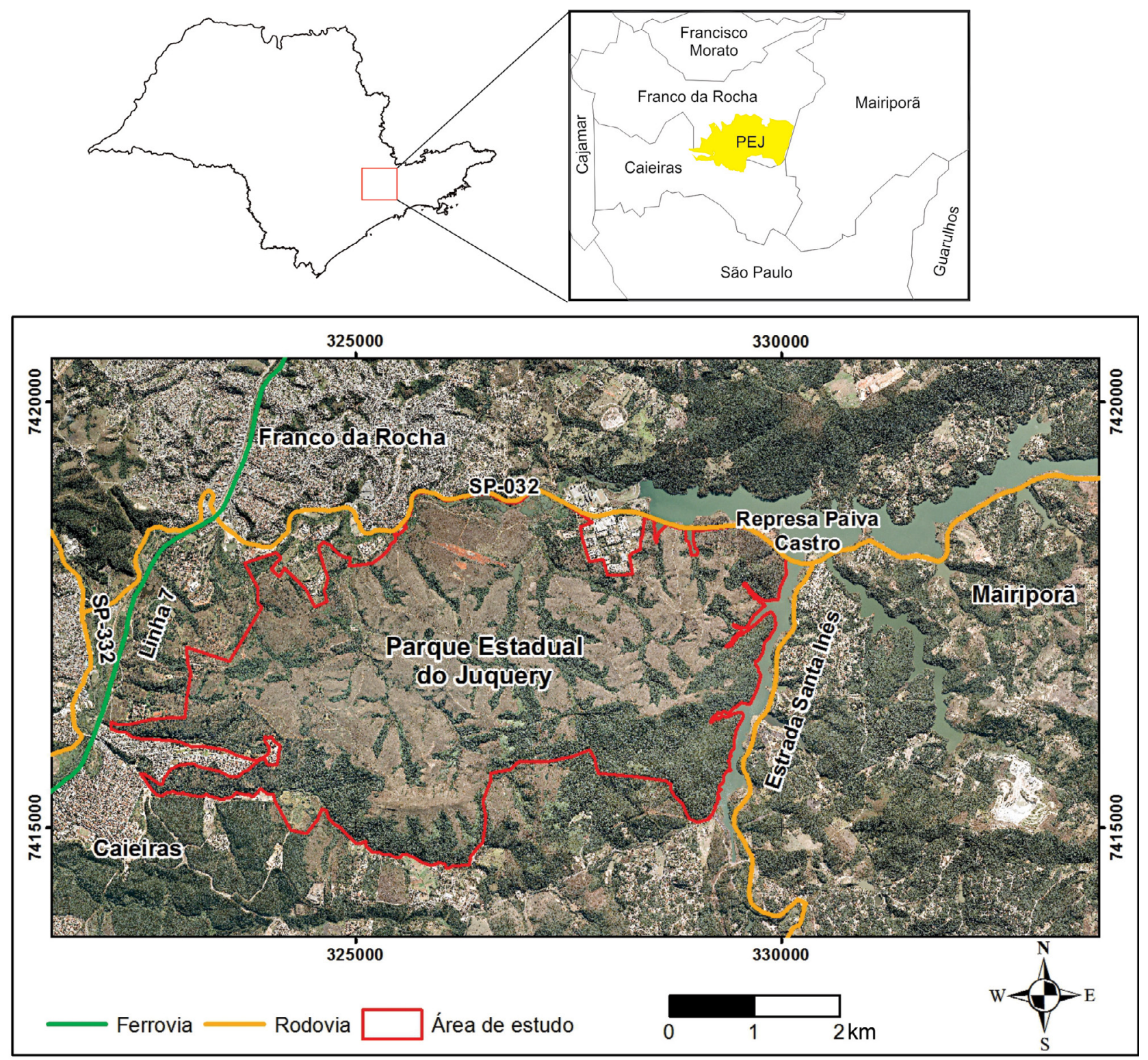

Ortofoto: EMPLASA, 2011

Figura 1. Localização do Parque Estadual do Juquery, as principais vias de acesso e seu entorno. 

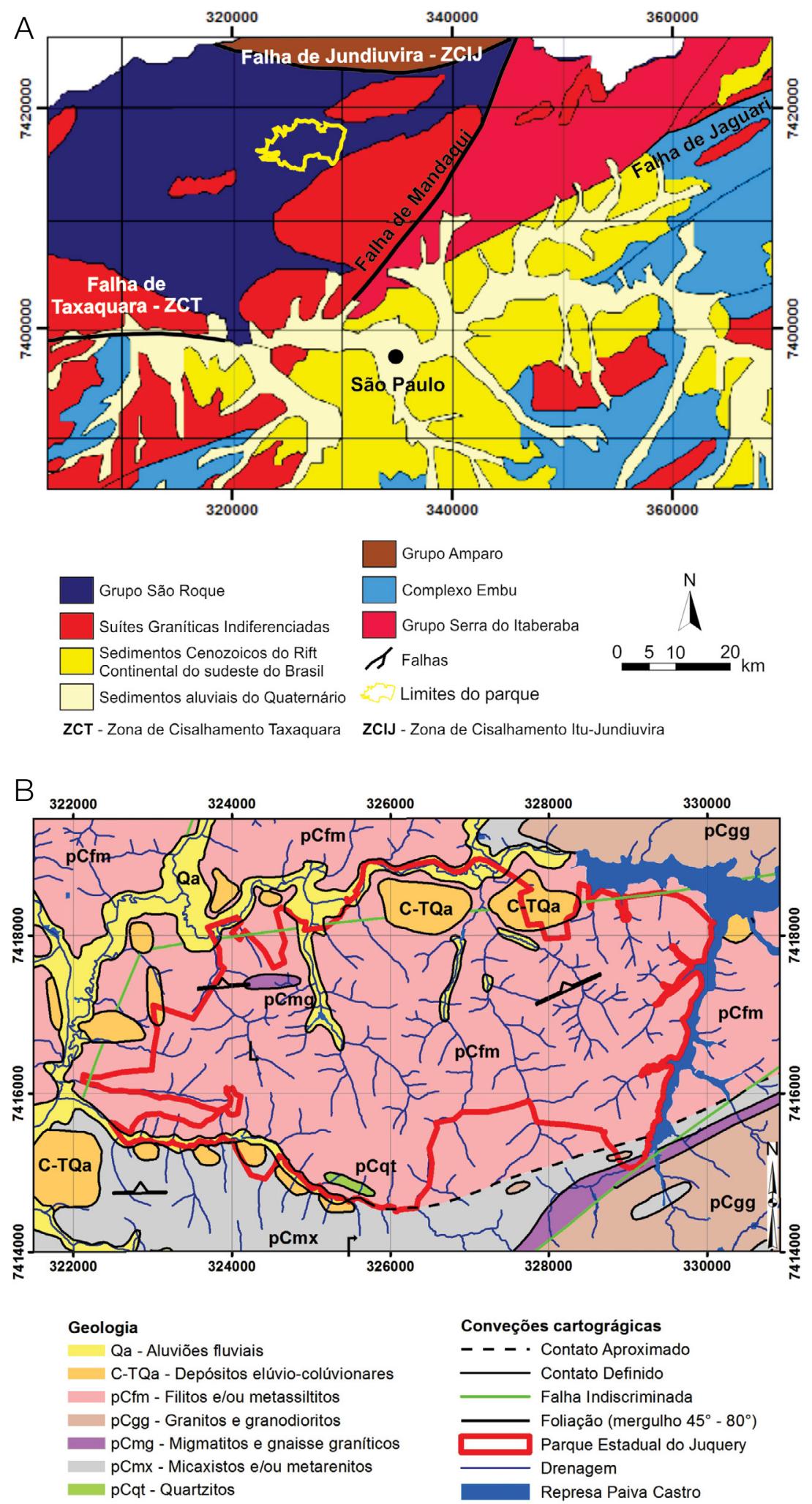

Conveções cartográgicas

- - - Contato Aproximado

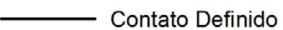

- Falha Indiscriminada

F Foliação (mergulho $45^{\circ}-80^{\circ}$ )

Parque Estadual do Juquery

Drenagem

Represa Paiva Castro

\section{\begin{tabular}{l}
$0 \quad 1.000 \quad 2.000 \mathrm{~m}$ \\
\hline
\end{tabular}}

Figura 2. (A) Geologia regional da área de estudo, destaque para as falhas que delimitam o Grupo São Roque. Modificado de Rodriguez (1998); (B) mMapa geológico da área do Parque Estadual do Juquery. Modificado de EMPLASA (1979). 
foliação S2 é caracterizada por uma clivagem de crenulação zonal a discreta. Segundo Hackspacher et al. (1993), a foliação S3 se expressa por meio de uma foliação milonítica, sendo difícil a distinção da clivagem ardosiana regional (S1).

Ao sul e ao norte, ocorrem zonas de cisalhamento com orientação regional segundo a direção NE-SW. A Zona de Cisalhamento Itu-Jundiuvira separa a porção norte do Grupo São Roque do Grupo Amparo; e a Zona de Cisalhamento Taxaquara limita-o do Complexo Embu (DNPM/CPRM, 1991; Hasui e Carneiro, 1980; Rodriguez, 1998; Takiya, 1997) (Figura 2).

A área de estudo está inserida na Unidade Morfoestrutural do Cinturão Orogênico do Atlântico, Província do Planalto Atlântico (Almeida, 1964), Zona da Serrania de São Roque (IPT, 1981). Os terrenos são caracterizados por Ab'Saber (1978) e Dantas (1990) como colinas dissecadas ou "mar de morros", e pelo Instituto de Pesquisas Tecnológicas (IPT, 1981) como morrotes alongados paralelos, limitados ao norte pela Serra do Japi e ao sul/sudeste pela terminação da Serra da Mantiqueira.

Segundo Ross e Moroz (1997), o relevo é composto por colinas e morros altos, topos aguçados e convexos, as formas são dissecadas com alta densidade de drenagem, os vales variam de entalhados a pouco entalhados. Luz (2010) descreve que os planaltos e as serras são compostos por serras alongadas, morros de topos convexos, com vertentes de declividade média a alta e planícies aluvionares restritas e isoladas.

Segundo Baitello et al. (2013), a partir do alto do Morro Grande é possível visualizar o relevo colinoso, com topo levemente arredondado, parecendo sucessões de meias laranjas, separados por pequenos vales. Ainda dentro do parque, Baitello et al. (2013) descrevem a ocorrência de trechos de topos retilíneos.

A Fundação de Apoio à Universidade de São Paulo (FUSP, 2009) afirma que a bacia do Rio Juqueri possui elevada densidade de drenagem e entalhamento dos vales, indicando alta fragilidade potencial do terreno, estando a área sujeita a processos erosivos do tipo linear e à ocorrência de movimentos de massas.

\section{Pedologia}

Segundo Oliveira et al. (1999), os solos predominantes na área de estudo são do tipo Argissolo Vermelho-Amarelo. Os argissolos, segundo definição da Empresa Brasileira de Pesquisa Agropecuária (EMBRAPA, 2006) são constituídos por argila de baixa ou alta atividade conjugada com caráter alítico ou saturação por base baixa, estando o horizonte B textural imediatamente abaixo dos horizontes A ou E.

Esses solos são caracterizados como de profundidade variável, de forte a imperfeitamente drenados, cores avermelhadas ou amareladas, raramente brunada ou cinzenta.
Quanto à textura, há um incremento de argila do horizonte A (arenosa a argilosa) para o horizonte Bt (média a muito argilosa), sendo a transição entre eles usualmente clara, abrupta ou gradual (EMBRAPA, 2006).

O Instituto Agronômico (IAC, 2014) apresenta uma caracterização similar para os argissolos, sendo esses descritos como solos minerais com diferenciação nítida entre camadas ou horizontes, verificados em campo pelo aumento abrupto nos teores de argila. Devido ao maior teor de argila conforme a profundidade aumenta, o solo passa a apresentar cor mais forte, também aumentando a coesão, a plasticidade e a pegajosidade.

Entre os diversos tipos de argissolos, o IAC (2014) destaca os de textura arenosa/média, média/argilosa e argilosa.

Os argissolos vermelhos e vermelho-amarelos de textura arenosa/média ocorrem em todo o Estado de São Paulo, oriundos de diversos materiais, exceto de rochas básicas e de rochas sedimentares finas. Baseado na associação entre as características de relevo (relativamente suavizado a ondulado), na natureza em superfície (pouco coesa), e na permeabilidade (menor nos horizontes subsuperficiais), os argilossolos podem ser classificados como de elevada suscetibilidade à erosão (IAC, 2014).

Os argissolos de textura média/argilosa e argilosa se desenvolvem frequentemente de rochas ígneas e metamórficas, quando no Planalto Atlântico, ou de rochas sedimentares finas (pelitos) em outras regiões. E, apesar da elevada capacidade de água disponível, podem apresentar limitações físicas no acondicionamento d'água, relacionadas à pouca profundidade e à presença de cascalhos ou calhaus em superfície, especialmente nos relevos mais íngremes do Planalto Atlântico (IAC, 2014).

Ferrari (2005) realizou sondagens na região da Central de Tratamento de Resíduos de Caieiras/Essencis, distante cerca de $3 \mathrm{~km}$ do PEJ, que constataram a presença de silte saprolítico de filito, sem observar rocha sã até os $70 \mathrm{~m}$ de profundidade (Figura 3).

A contextualização geológica, geomorfológica e pedológica permite analisar de forma integrada as variáveis do meio físico, que refletem diretamente no comportamento geotécnico das unidades mapeadas e, consequentemente, nos processos morfodinâmicos analisados neste estudo.

\section{MATERIAIS E MÉTODOS}

Para a realização da pesquisa, foram utilizados como insumos diversos dados secundários: folhas topográficas, fotografias aéreas e mapas temáticos (geologia, geomorfologia e pedologia), conforme descrito a seguir:

- folhas topográficas em escala 1:10.000 (EMPLASA, 1980), com curvas de nível equidistantes em $5 \mathrm{~m}$ : Franco da Rocha (SCM-3413/SF-23-Y-C-III-4-NO-C), bairro 
dos Valos (SCM- 3414/SF-23-Y-C-III-4-NO-D), Caieiras (SCM-3415/SF-23-Y-C-III-4-NO-E) e Vila Machado (SCM-3416/SF-23-Y-C-III-4-NO-F);

- fotografias aéreas, com estereoscopia e resolução espacial de aproximadamente $0,45 \mathrm{~m}$, dos anos de 2010 e 2011, referentes ao Projeto Mapeia São Paulo (EMPLASA, 2011);

- fotografias aéreas com escala equivalente a 1:8.000, dos anos de 1976 e 1977 (EMPLASA, 1977);

- folha 34 da Carta Geológica da Região Metropolitana de São Paulo (escala 1:50.000) (EMPLASA, 1979);

- mapa geomorfológico do Estado de São Paulo, escala de 1:1.000.000 (IPT, 1981);

- mapa pedológico do Estado de São Paulo, escala de 1:500.000 (Oliveira et al., 1999).

Devido à disparidade de classificação dos produtos disponíveis, foi necessário definir a escala de trabalho (1:20.000) e, consequentemente, adequar toda a base de dados, de modo que os resultados fossem compatíveis com as necessidades do parque, fornecendo informações com nível de detalhe intermediário para auxiliar no desenvolvimento de instrumentos de gestão do uso do solo no PEJ.

Com base nos insumos descritos, iniciou-se a etapa de preparação do material cartográfico (elaboração de base topográfica e geração do modelo numérico de terreno), caracterização geológico-geotécnica, para posterior avaliação de suscetibilidade das unidades aos processos erosivos e de movimentação gravitacional de massa.

\section{Elaboração da base topográfica}

Após a definição da escala de pesquisa (1:20.000), foi necessário adequar a base topográfica atendendo às condições limites para elaboração de cartas de declividade propostas por Zuquette e Gandolfi (2004).
Para tanto, utilizou-se o software ArcGis 10.1 para georreferenciamento das folhas topográficas e posterior vetorização das curvas de nível, bem como dos cursos d'água existentes, representados pelas drenagens e represas.

\section{Geração do modelo numérico de terreno}

Os produtos resultantes dessa etapa auxiliaram na avaliação da suscetibilidade aos processos erosivos e de movimentação gravitacional de massa.

A partir das curvas de nível vetorizadas, foi gerado o Modelo Numérico do Terreno (MNT), por meio da ferramenta "Create TIN" (3D Analyst) do referido software. Para a elaboração do mapa hipsométrico, foram configuradas as propriedades do TIN, sendo definidas 10 classes, com intervalo de $22 \mathrm{~m}$.

Quanto ao mapa de declividade, o procedimento foi similar, sendo que, a partir da ferramenta "Face Slope with graduated color ramp", definiram-se o número de classes e o intervalo de interesse. Foram elaborados três mapas de declividade, o primeiro visa auxiliar na caracterização e delimitação das unidades geológico-geotécnicas e adotou os intervalos: 0 a $5 \%$; 5 a $15 \% ; 15$ a $30 \% ; 30$ a $50 \%$; e 50 a $100 \%$; os outros dois são específicos para auxiliar na análise de suscetibilidade aos processos erosivos e de movimentação gravitacional de massa, e adotaram, respectivamente, os intervalos: 0 a $5 \% ; 5$ a $15 \%$ e $>15 \%$ e, 0 a $30 \%, 30$ a $50 \%$ e $>50 \%$, conforme proposto por Cerri et al. (2006) e Amorim (2012).

\section{Caracterização geológico-geotécnica}

Essa etapa consistiu na compartimentação da área do parque em unidades que possuem, internamente, características geológicas e comportamento geotécnico semelhantes.

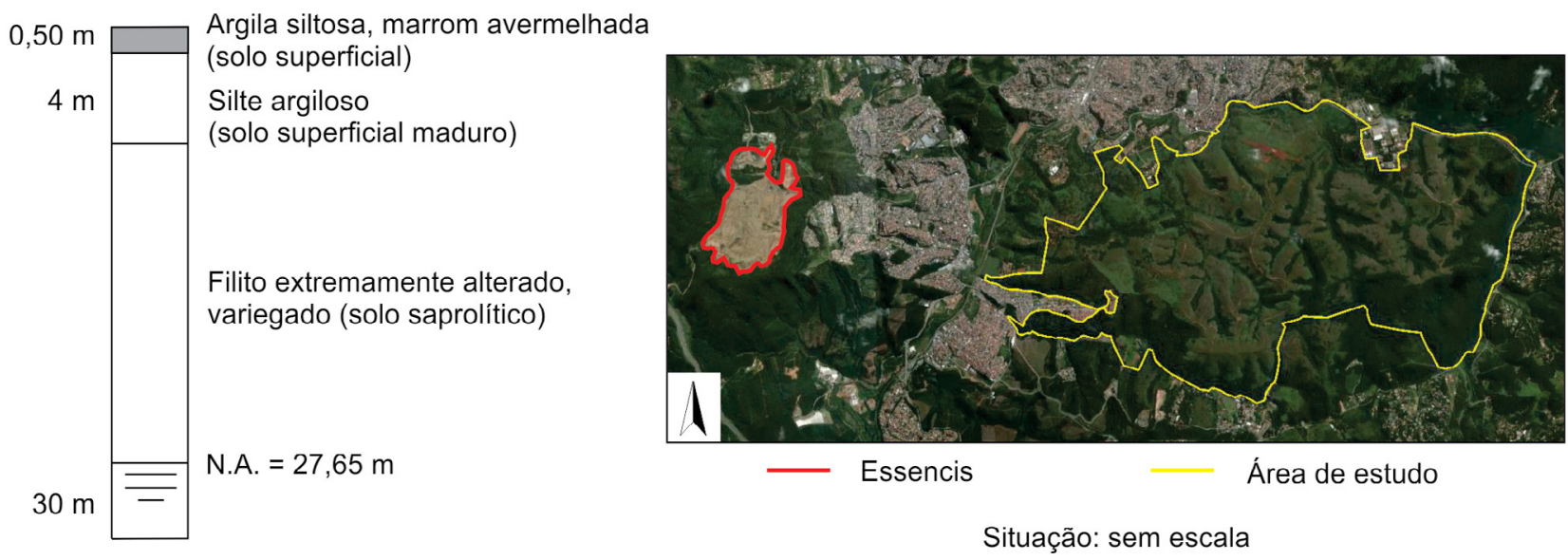

Figura 3. Perfil de sondagem representativa da região da Central de Tratamento de Resíduos de Caieiras/Essencis em relação à localização do Parque Estadual do Juquery. 
A caracterização foi realizada por meio de análise integrada, com aquisição de dados primários durante etapa de campo, associada às informações geradas pelo modelo numérico de terreno (declividade e hipsometria) e utilização de técnicas de fotointerpretação, além de consulta a dados secundários, como geologia, geomorfologia e pedologia.

\section{Avaliação de suscetibilidade aos processos erosivos e de movimentos gravitacionais de massa}

Segundo o IPT (2014), suscetibilidade pode ser definida como a predisposição ou a propensão de um determinado terreno ao desenvolvimento de um processo do meio físico. Quanto às técnicas disponíveis, Souza e Sobreira (2014) apontam que as principais se baseiam em procedimentos heurísticos ou empíricos, determinísticos e estatísticos, e sua escolha depende da existência e da qualidade dos dados necessários. Neste trabalho, apesar do maior grau de subjetividade, optou-se pelo método empírico, visto que ele demonstra vantagem sobre os outros.

A avaliação das unidades quanto à suscetibilidade a processos erosivos e de movimentos de massa baseia-se na utilização de técnicas para avaliar condicionantes do meio físico, e tem como insumo a caracterização geológico-geotécnica das unidades, que, apesar de não ser o objetivo deste artigo, apresenta informações imprescindíveis para a avaliação dos processos geológicos atuantes na área estudada.

Os processos erosivos analisados são do tipo linear, divididos em:

- sulco - pequenas incisões/canais formados pelo fluxo de água;

- ravina - evolução do processo de sulco, por aprofundamento, apresentando entalhamento vertical;

- boçoroca - estágio avançado no qual o fluxo superficial avança até o nível de fluxo subterrâneo e esses, juntos, têm alto poder de destruição (DAEE, 1990; Infanti Junior e Fornasari Filho, 1998).

Para tanto, recorreu-se ao levantamento de dados secundários, advindos de áreas como geologia, geomorfologia, pedologia, declividade, altimetria e, principalmente, da fotointerpretação associada aos dados primários coletados em campo (análise táctil-visual dos perfis típicos de alteração, litologia, tipos e formas de relevo e registro dos processos morfodinâmicos).

A Tabela 1 apresenta os parâmetros utilizados para avaliação e classificação qualitativa dos terrenos, em relação aos processos de erosão hídrica linear, e a Tabela 2, para os processos de movimentos gravitacionais de massa, ambos separados em

Tabela 1. Parâmetros adotados para avaliação dos processos de erosão hídrica linear.

\begin{tabular}{|c|c|c|c|c|}
\hline \multicolumn{2}{|c|}{ Fatores } & Baixa & Moderada & Alta \\
\hline \multirow{3}{*}{ 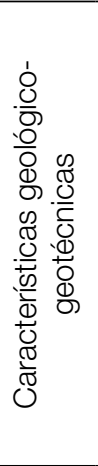 } & $\begin{array}{l}\text { Tipo e } \\
\text { espessura do } \\
\text { solo }\end{array}$ & $\begin{array}{l}\text { - Solo argiloso e pouco } \\
\text { espesso }(<2 \mathrm{~m}) \text { ou área } \\
\text { de afloramento de rocha }\end{array}$ & $\begin{array}{l}\text { - Solo arenoso e areno- } \\
\text { argiloso, com espessuras } \\
\text { médias ( } 2 \text { a } 5 \text { m) }\end{array}$ & $\begin{array}{l}\text { - Solo arenoso e areno-siltoso espesso } \\
(>5 \mathrm{~m})\end{array}$ \\
\hline & $\begin{array}{l}\text { Declividade } \\
\text { dominante do } \\
\text { terreno }\end{array}$ & $\begin{array}{l}\text { - Suave }(<5 \%) \text { em altos } \\
\text { topográficos e baixadas }\end{array}$ & $\begin{array}{l}\text { - Moderada (5 a 15\%) em } \\
\text { meia encosta }\end{array}$ & $\begin{array}{l}\text { - Alta (> 15\%) em meia encosta ou } \\
\text { cabeceiras de drenagens }\end{array}$ \\
\hline & $\begin{array}{l}\text { Escoamento } \\
\text { superficial } \\
\text { (densidade } \\
\text { versus } \\
\text { organização) }\end{array}$ & $\begin{array}{l}\text { - Pequena área de } \\
\text { contribuição a montante } \\
\text { - Domínio de escoamento } \\
\text { laminar em áreas } \\
\text { dispersoras de água } \\
\text { - Alta densidade textural }\end{array}$ & $\begin{array}{l}\text { - Área de contribuição a } \\
\text { montante de médio porte } \\
\text { - Linhas de concentração } \\
\text { de fluxo de água reduzido }\end{array}$ & $\begin{array}{l}\text { - Grande área de contribuição (deflúvio) } \\
\text { a montante } \\
\text { - Domínio de escoamento concentrado } \\
\text { com formação de canais preferenciais e } \\
\text { incisão de talvegue } \\
\text { - Baixa densidade textural }\end{array}$ \\
\hline 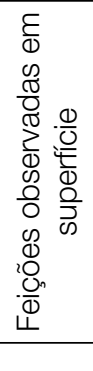 & $\begin{array}{l}\text { Indícios de } \\
\text { erosão e } \\
\text { concentração } \\
\text { de águas } \\
\text { pluviais } \\
\text { (enxurradas). }\end{array}$ & $\begin{array}{l}\text { - Poucos sulcos erosivos, } \\
\text { rasos e esparsos }\end{array}$ & $\begin{array}{l}\text { - Sulcos erosivos } \\
\text { generalizados na faixa } \\
\text { de domínio das estradas } \\
\text { e/ou trilhas } \\
\text { - Acúmulo de materiais } \\
\text { erodidos na faixa de } \\
\text { domínio da estrada e/ } \\
\text { ou trilha (depósitos de } \\
\text { assoreamento) }\end{array}$ & $\begin{array}{l}\text { - Marcante presença de sulcos erosivos } \\
\text { generalizados, profundos, podendo } \\
\text { ocorrer também ravinas e boçorocas } \\
\text { - Surgências d'água nas erosões } \\
\text { profundas } \\
\text { - Acumulação significativa de materiais } \\
\text { erodidos na faixa de domínio das } \\
\text { estradas e trilha }\end{array}$ \\
\hline \multicolumn{2}{|c|}{ Cobertura vegetal } & $\begin{array}{l}\text { - Sem áreas significativas } \\
\text { de solo exposto }\end{array}$ & $\begin{array}{l}\text { - Cobertura vegetal } \\
\text { deficiente com áreas } \\
\text { significativas de solo } \\
\text { exposto }\end{array}$ & - Predomínio de áreas de solo exposto \\
\hline
\end{tabular}

Fonte: Adaptado de Cerri et al. (2006) e Amorim (2012). 
baixa, moderada e alta possibilidade de ocorrência, segundo proposto por Cerri et al. (2006) e Amorim (2012).

A consolidação da classificação foi realizada a partir da análise gráfica, segundo Martins (2012) e Rodrigues et al. (2014), que consiste na análise combinatória das variáveis, partindo do pressuposto de que todos os parâmetros avaliados possuem a mesma relevância quanto à suscetibilidade aos processos. Foram adotados 5 e 4 variáveis de interesse, respectivamente, para os processos erosivos e de movimentos de massa. Do total de 81 e 243 combinações diferentes, foram adotadas 15 e 21 possibilidades, uma vez que a ordem das variáveis não interfere na análise, hierarquizados em três classes: baixa (verde), moderada (amarelo) e alta (vermelho) (Tabelas 3 e 4).

A apresentação dos resultados ocorre por meio de tabelas e mapas individualizados de acordo com o tipo de processo geológico, em conjunto com análise quantitativa dos registros realizados em campo e em fotointerpretação, bem como com caracterização individualizada de cada unidade quanto à suscetibilidade aos processos analisados.

\section{RESULTADOS E DISCUSSÃO}

\section{Caracterização geológico-geotécnica}

A área de estudo foi subdividida em seis unidades:

1. A-Quartzitos e filitos em relevo de morros altos;

2. B - Filitos em meio a veios de quartzo em relevo de morros altos;

3. C-Filitos com intercalações arenosas em relevo de morros baixos;

4. D - Rampas de colúvio;

5. E-Planícies aluvionares; e

6. F-Depósito de tálus em sopé de encosta.

E uma subunidade geológico-geotécnica:

- $\mathrm{C} 1$ - Cabeceiras de drenagem (Figura 4).

Para complementar a caracterização, foram integradas ao mapa informações extraídas de fotografias aéreas e das observações de campo (cabeceiras em anfiteatro e boçorocas).

Tabela 2. Parâmetros adotados para avaliação dos processos de movimentação gravitacional de massa.

\begin{tabular}{|c|c|c|c|c|}
\hline \multicolumn{5}{|c|}{ Possibilidade de ocorrência de processos de movimentação gravitacional de massa } \\
\hline & Fatores & Baixa & Moderada & Alta \\
\hline 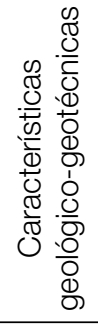 & $\begin{array}{l}\text { Declividade do } \\
\text { terreno }\end{array}$ & $\begin{array}{l}\text { - Declividade suave a } \\
\text { moderada }(<30 \%) \\
\text { - Solos / materiais } \\
\text { argilosos e arenosos } \\
\text { pouco espessos ou com } \\
\text { rocha subaflorante }\end{array}$ & $\begin{array}{l}\text { - Solos / materiais } \\
\text { arenosos e argilosos } \\
\text { espessos }\end{array}$ & $\begin{array}{l}\text { - Declividade acentuada (> 50\%) } \\
\text { - Predomínio de áreas de solo } \\
\text { exposto } \\
\text { - Estruturas geológicas } \\
\text { desfavoráveis } \\
\text { - Solos/materiais argilosos e } \\
\text { arenosos espessos }\end{array}$ \\
\hline 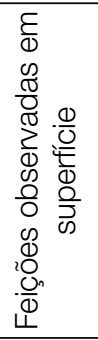 & $\begin{array}{l}\text { Queda de blocos ou } \\
\text { núcleos rochosos } \\
\text { Indícios de } \\
\text { movimentação: } \\
\text { árvores e postes } \\
\text { inclinados; trincas no } \\
\text { solo/aterro, degraus } \\
\text { de abatimento etc. }\end{array}$ & $\begin{array}{l}\text { - Ausência de blocos ou } \\
\text { núcleos rochosos } \\
\text { - Não há indícios de } \\
\text { movimentação }\end{array}$ & $\begin{array}{l}\text { - Raros blocos rochosos } \\
\text { no solo/cortes } \\
\text { - Indícios de } \\
\text { movimentação localizados } \\
\text { (árvores e postes } \\
\text { inclinados), sem a presença } \\
\text { de trincas no terreno }\end{array}$ & $\begin{array}{l}\text { - Presença de blocos/núcleos } \\
\text { rochosos } \\
\text { - Indícios de movimentação } \\
\text { generalizados, incluindo trincas no } \\
\text { terreno, degraus de abatimento, } \\
\text { afundamentos na crista e } \\
\text { estufamentos na base do talude } \\
\text { - Áreas saturadas ou presença de } \\
\text { surgências d'água }\end{array}$ \\
\hline
\end{tabular}

Fonte: Adaptado de Cerri et al. (2006) e Amorim (2012).

Tabela 3. Análise gráfica das combinações possíveis para análise da suscetibilidade à erosão hídrica linear.

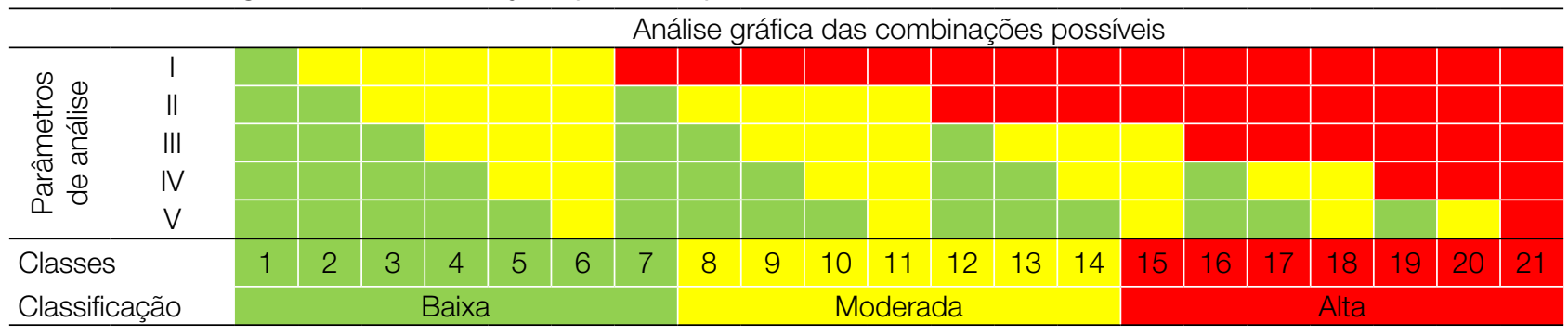

Fonte: Adaptado de Martins (2012) e Rodrigues et al. (2014). 


\section{Análise dos processos morfodinâmicos identificados}

Com base nas características fisiográficas identificadas previamente à etapa de campo, foram considerados os processos de assoreamento, enchente, inundação, alagamento, erosão (sulco, ravina e boçoroca) e movimentos de massa (rastejo, escorregamentos e quedas), fundamentando-se nas definições de Infanti Junior e Fornasari Filho (1998) e Augusto Filho (1992) durante a execução desta pesquisa.

Tabela 4. Análise gráfica das combinações possíveis para análise da suscetibilidade aos movimentos gravitacionais de massa.

\begin{tabular}{|c|c|c|c|c|c|c|c|c|c|c|c|c|c|c|c|c|}
\hline \multicolumn{17}{|c|}{ Análise gráfica das combinações possíveis } \\
\hline \multirow{4}{*}{ 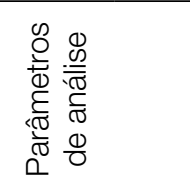 } & I & & & & & & & & & & & & & & & \\
\hline & $\|$ & & & & & & & & & & & & & & & \\
\hline & III & & & & & & & & & & & & & & & \\
\hline & IV & & & & & & & & & & & & & & & \\
\hline \multirow{2}{*}{\multicolumn{2}{|c|}{$\begin{array}{l}\text { Classes } \\
\text { Classificação }\end{array}$}} & 1 & 2 & 3 & 4 & 5 & 6 & 7 & 8 & 9 & 10 & 11 & 12 & 13 & 14 & 15 \\
\hline & & \multicolumn{5}{|c|}{ Baixa } & \multicolumn{5}{|c|}{ Moderada } & \multicolumn{5}{|c|}{ Alta } \\
\hline
\end{tabular}

Fonte: Adaptado de Martins (2012) e Rodrigues et al. (2014).

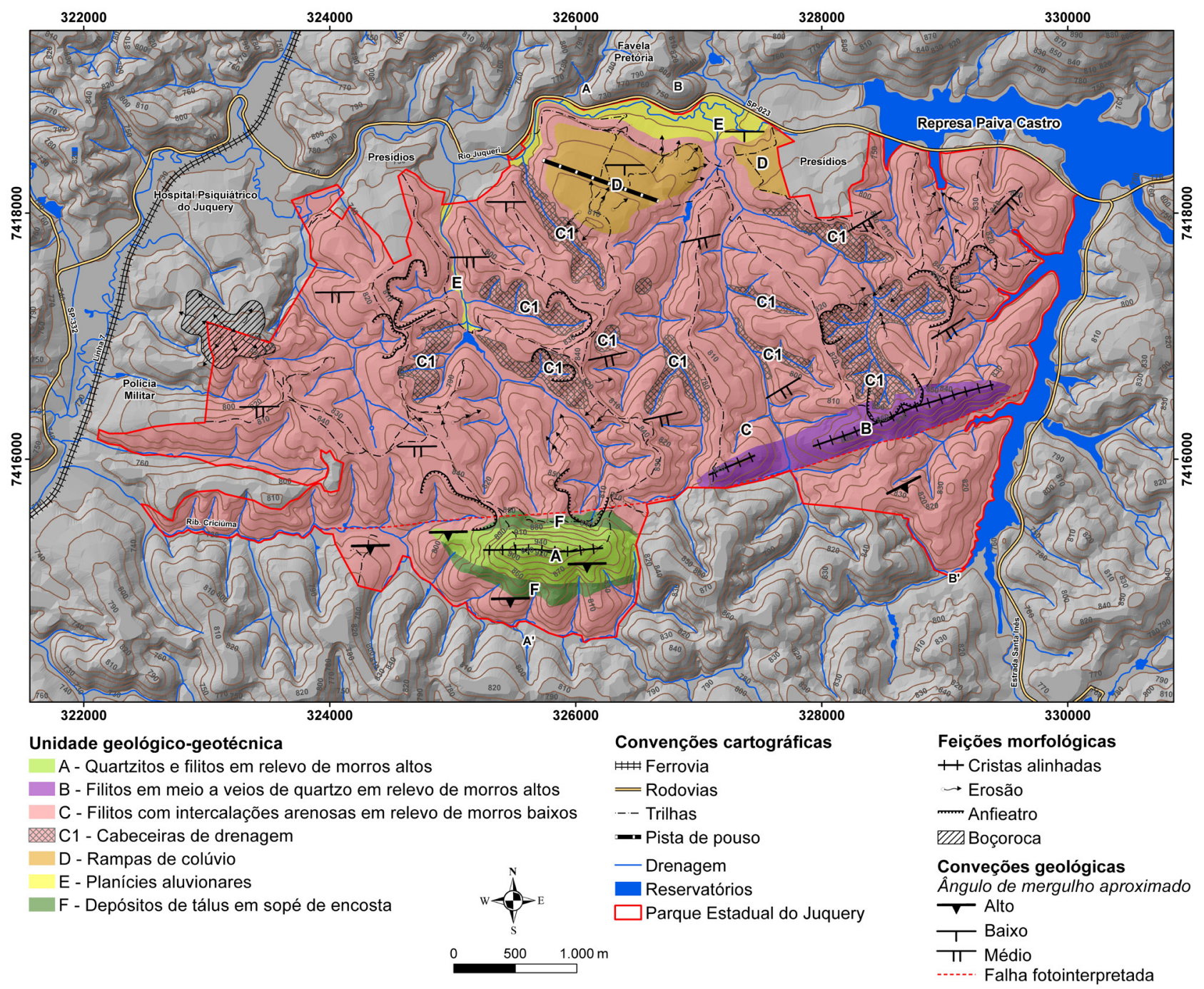

Figura 4. Mapa geológico-geotécnico do Parque Estadual do Juquery. 
A Tabela 5 e a Figura 5 apresentam a frequência e a distribuição de cada tipo de processo identificado em relação às unidades geológico-geotécnicas.

No total, foram registrados 39 processos morfodinâmicos, dos quais 95\% (37 ocorrências) são processos erosivos (sulcos, ravinas e boçoroca) ou movimentos gravitacionais de massa (rastejo, quedas e escorregamento) e $5 \%$ (duas ocorrências) são de assoreamento e enchente.

Os processos erosivos representam $56 \%$ do total, enquanto $38 \%$ dos registros estão associados aos processos

Tabela 5. Relação entre a ocorrência de processos morfodinâmicos e as unidades.

\begin{tabular}{|c|c|c|c|c|c|c|c|}
\hline Unidades geológico-geotécnicas & 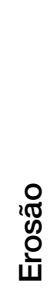 & 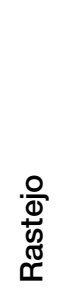 & 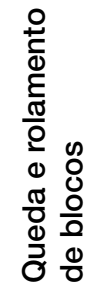 & 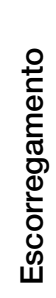 & 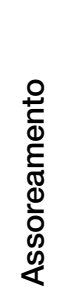 & 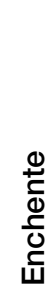 & $\begin{array}{l}\bar{\sigma} \\
\stackrel{\sigma}{\circ}\end{array}$ \\
\hline A - Quartzitos e filitos em relevo de morros altos & 3 & 1 & 5 & - & - & - & 9 \\
\hline B - Filitos em meio a veios de quartzo em relevo de morros altos & 2 & - & 2 & - & - & - & 4 \\
\hline C - Filitos com intercalações arenosas em relevo de morros baixos & 9 & - & 1 & 1 & - & - & 11 \\
\hline C1-Cabeceiras de drenagem & - & - & - & - & - & - & - \\
\hline D - Rampas de colúvio & 4 & - & - & - & - & - & 4 \\
\hline E - Planícies aluvionares & - & - & - & - & 1 & 1 & 2 \\
\hline F - Depósito de tálus em sopé de encosta & 4 & - & 5 & - & - & - & 9 \\
\hline Total & 22 & 1 & 13 & 1 & 1 & 1 & 39 \\
\hline
\end{tabular}

\section{Relação entre processos geológico e unidades} mapeadas

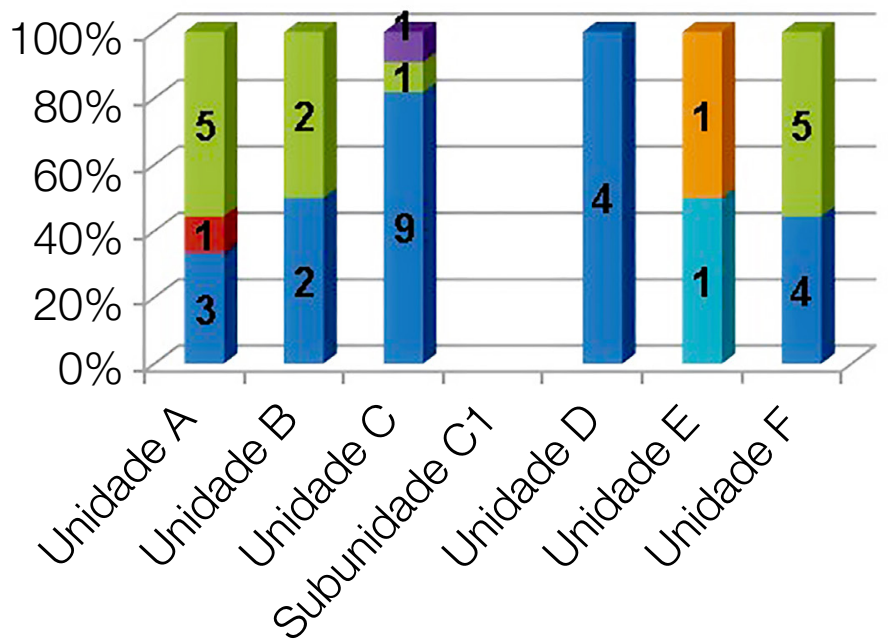

- Enchente

- Assoreamento

- Escorregamento

- Queda de bloco

- Rastejo

- Erosão

Figura 5. Distribuição dos processos identificados e sua correlação com as unidades. 
de movimentos de massa (rastejo, escorregamento, queda e rolamento de blocos).

Devido ao alto índice de ocorrência de processos erosivos e de movimentos gravitacionais de massa, este estudo restringiu a análise de suscetibilidade das unidades geológico-geotécnicas segundo esses processos.

\section{Avaliação de suscetibilidade aos processos erosivos}

A avaliação consiste em analisar cada unidade em relação aos fatores apresentados anteriormente na Tabela 1.

Para cada unidade, a classificação parcial, atribuída a cada fator, e a classificação final obtida pela análise combinatória desses fatores são apresentadas na Tabela 6. Tal representação é baseada em cores semafóricas (verde, amarelo e vermelho) atreladas à classificação das unidades quanto à suscetibilidade aos processos erosivos (baixa, moderada e alta).

A consolidação da análise constatou que $95 \%$ da área possuem moderada suscetibilidade aos processos erosivos e que $5 \%$ são consideradas de alta suscetibilidade, conforme apresentado na Figura 6. Entretanto, constatou-se que a aplicação do método de avaliação das unidades não foi suficiente para classificar as áreas do parque de modo satisfatório, pois não abrangeu dois setores críticos observados em campo. Tais setores não foram apontados devido ao método adotado se limitar a classificar as unidades de forma homogênea, não identificando feições pontuais.

Desse modo, o modelo obtido foi ajustado considerando informações coletadas in situ, atribuindo à porção oeste da Unidade C, especificamente para o local de ocorrência da boçoroca, classificação alta em relação aos processos erosivos.

O outro setor crítico é caracterizado por ravinas no leito da estrada e ocorre na porção nordeste do parque, sendo apenas delimitado e apontado no mapa como "setor crítico", mantendo-se a classificação geral da unidade.

\section{Avaliação de suscetibilidade aos processos de movimentos de massa}

As mesmas etapas adotadas para a avaliação de suscetibilidade aos processos erosivos foram utilizadas para os movimentos gravitacionais de massa, sendo que, nesse caso, cada unidade foi analisada em relação aos fatores apresentados anteriormente na Tabela 2.

Para cada unidade foi realizada classificação parcial, atribuída a cada fator, e a classificação final pode ser visualizada na Tabela 7. Tal representação segue a proposta de utilização de cores semafóricas (verde, amarelo e vermelho) para a classificação das unidades quanto à suscetibilidade aos processos de movimentação gravitacional de massa (baixa, moderada e alta).

A Figura 7 consolida a análise realizada e indica que $88 \%$ da área de estudo possuem baixa suscetibilidade aos processos de movimentação gravitacional de massa e que $12 \%$ têm moderada suscetibilidade, não sendo identificadas unidades com alta suscetibilidade aos processos avaliados.

Essa relação se deve, principalmente, à baixa declividade predominante em todas as unidades do parque, uma vez que, apesar de todos os fatores avaliados possuírem a mesma relevância, a declividade é um fator balizador para a deflagração de processos dessa natureza.

\section{Caracterização das unidades mapeadas quanto à suscetibilidade aos processos erosivos e de movimentação gravitacional de massa}

A classificação das unidades geológico-geotécnicas quanto à suscetibilidade aos processos identificados é apresentada a seguir.

Tabela 6. Resultado da avaliação da suscetibilidade à erosão.

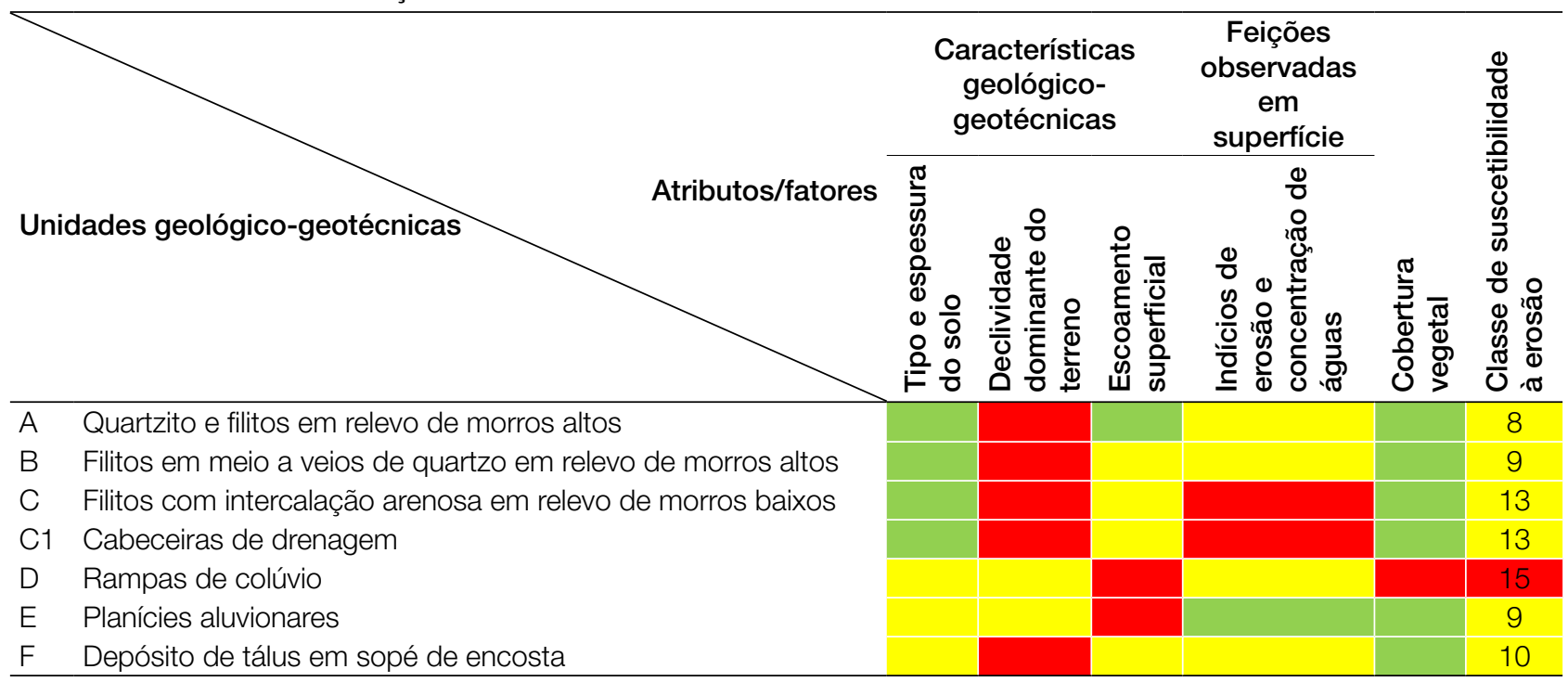




\section{Unidade A: Quartzito e filitos em relevo de morros altos}

Considerada como de moderada suscetibilidade aos processos erosivos e de movimentos de massa, essa unidade se caracteriza pelo perfil de solo pouco desenvolvido, moderada resistência à erosão e declividade acentuada.

Pôde ser constatado que a trilha se comporta como um agente deflagrador de processos erosivos, uma vez que a exposição do solo gera um caminho preferencial para o escoamento superficial, não sendo visualizados sulcos e ravinas fora dos limites da trilha (Figura 8).

Portanto, as alterações de traçado nas trilhas devem ser estudadas e levadas em consideração como sendo um agente deflagrador de processos erosivos, em uma área naturalmente com moderada suscetibilidade. Também deve ser considerada a possibilidade de estruturar a trilha com obras de infraestrutura para minimizar os impactos observados.

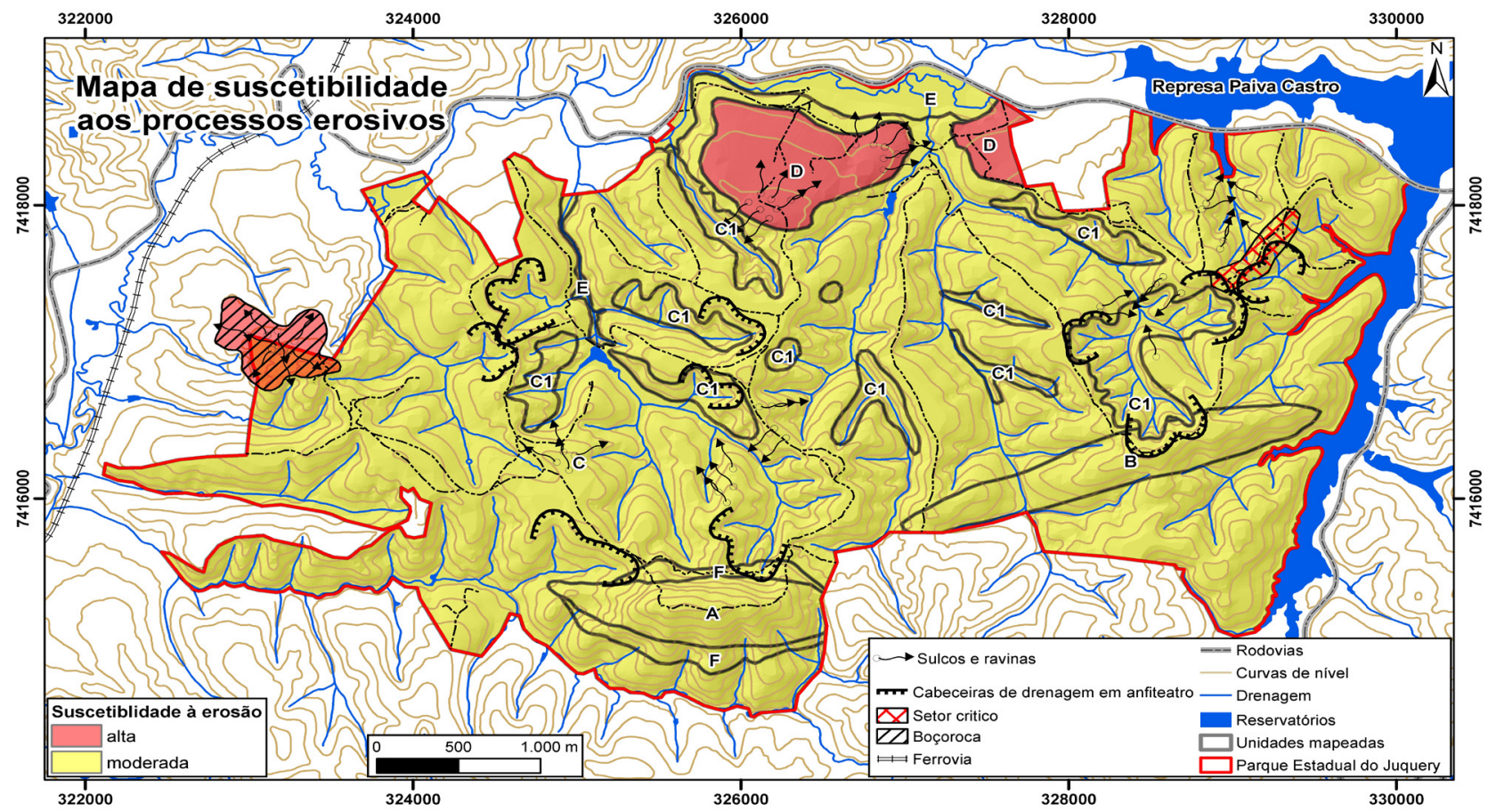

Figura 6. Mapa de suscetibilidade aos processos erosivos.

Tabela 7. Resultado da avaliação da suscetibilidade aos processos de movimentação gravitacional de massa.

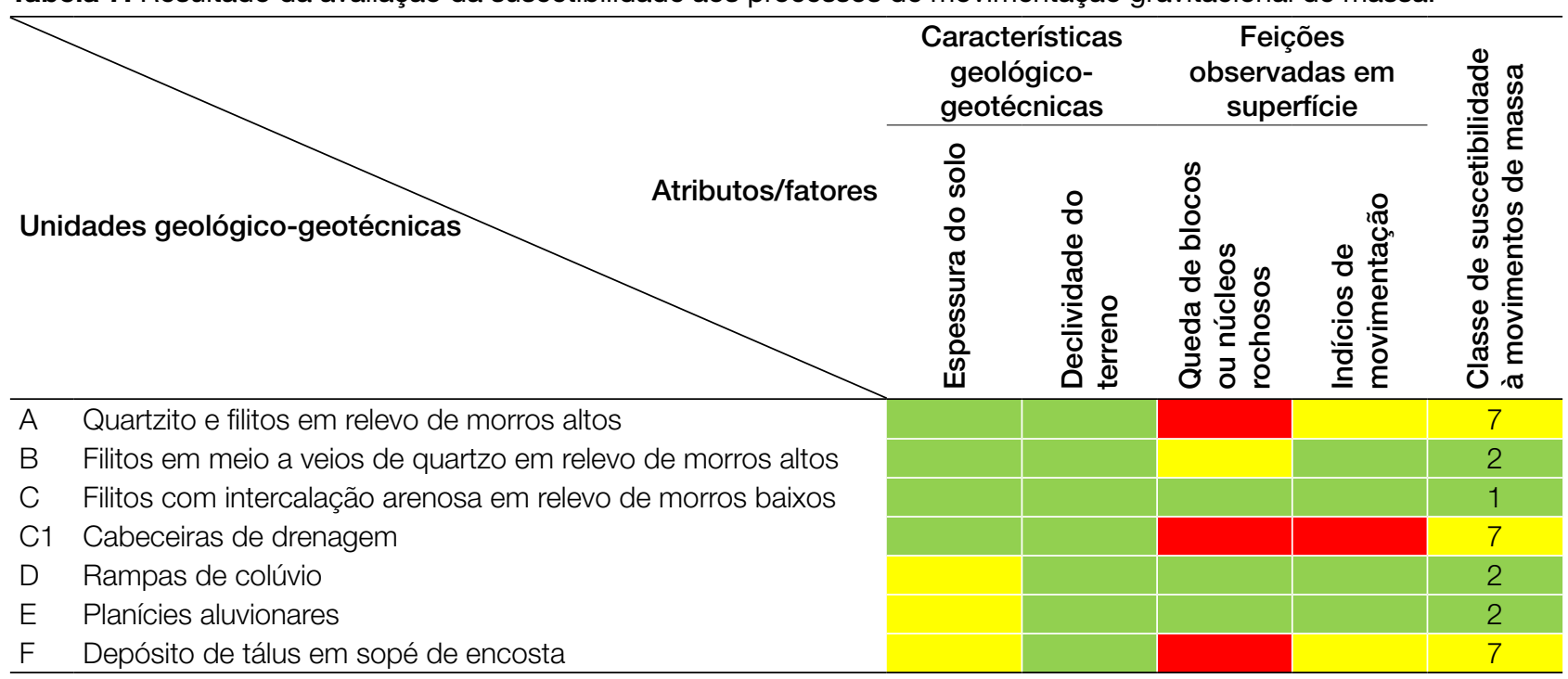




\section{Unidade B: Filitos em meio a veios} de quartzo em relevo de morros altos

Caracterizada como de moderada suscetibilidade aos processos erosivos e baixa suscetibilidade aos processos de movimentação gravitacional de massa, a unidade possui perfil de solo incipiente, com alta declividade para processos erosivos, considerando os intervalos adotados.

O uso do solo é composto por vegetação rasteira que recobre toda a unidade, exceto as estradas, em que foi possível observar nas laterais processos erosivos devido à concentração do fluxo hídrico superficial, o que provocou sulcos e ravinas. Portanto, as estradas atuam como agente deflagrador, uma vez que não foram visualizadas feições erosivas fora do leito das estradas.

Também foram identificados blocos rolados (Figura 9) que, associados aos veios de quartzo, possuem maior resistência à erosão em relação aos filitos e tendem a se dispersar por ação gravitacional para áreas a jusante.

Deve ser considerada também a possibilidade de estruturar as estradas com obras de infraestrutura para disciplinar o fluxo hídrico concentrado, de modo a minimizar os impactos dos processos identificados.

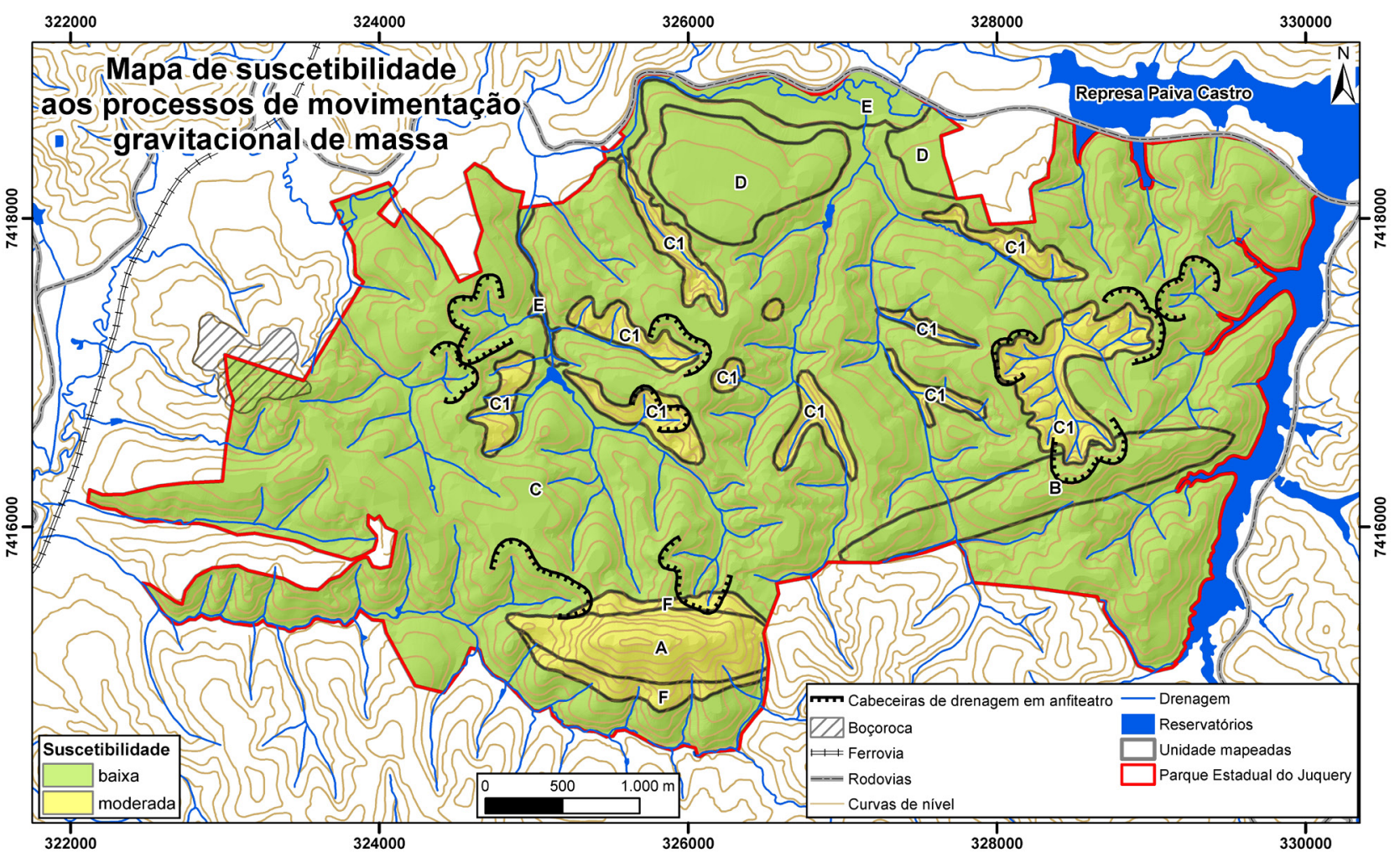

Figura 7. Mapa de suscetibilidade aos processos de movimentos de massa.
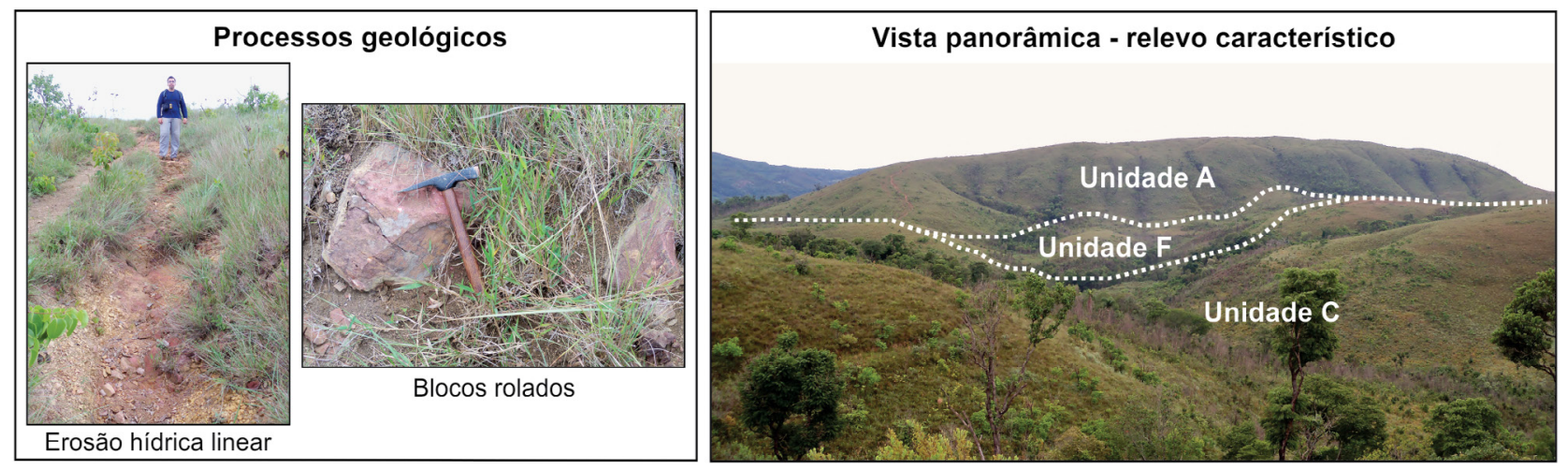

Figura 8. Registro de processos erosivos e rolamento de blocos na Unidade A. 


\section{Unidade C: Filitos com intercalação arenosa em relevo de morros baixos}

A unidade é representada por terreno de relevo dissecado, com perfil de solo pouco desenvolvido, declividade alta para processos erosivos e controle estrutural que orienta as feições de relevo. Foi considerada em relação aos processos erosivos como de moderada suscetibilidade, e para processo de movimentação gravitacional de massa, como de baixa suscetibilidade.

Destaca-se que essa unidade representa $78 \%$ da área do parque, e que dos processos identificados em campo, $80 \%$ referem-se aos processos erosivos. Com relação ao uso do solo, de maneira geral a unidade é recoberta por vegetação rasteira com áreas pontuais de solo exposto.

Para essa unidade, observaram-se dois processos de erosão hídrica em estágio avançado (Figura 10): um dos processos determinou a classificação de uma área que associada a uma boçoroca se caracteriza como de alta suscetibilidade à erosão; o outro determinou a classificação de um trecho de estrada com ravinas disseminadas como setor crítico.

Assim como nas demais unidades, os processos erosivos identificados na área de estudo se concentram por caminhos preferenciais criados por condicionantes antrópicos, nesse caso por estradas e pontualmente por uma antiga área de empréstimos, onde se desenvolveu uma boçoroca.

A única diferença observada entre o trecho de estrada, considerado como setor crítico, e os demais é sua orientação, que coincide com a direção da foliação principal (NE-SW). Nesse caso, a deflagração dos processos possivelmente está associada à diferença de resistência à erosão das camadas do filito, que podem gerar caminhos preferenciais concentrando o escoamento superficial.

Analisando as imagens de 1976/1977 e 2010/2011 é possível observar que a boçoroca está localizada no mesmo local onde havia grande movimentação de solo na década de 1970 (Figura 11). A evolução da boçoroca teria se iniciado devido a um caminho preferencial originado por uma área de empréstimo, utilizada para fornecer material para a abertura de estradas nas proximidades do Hospital Psiquiátrico do Juquery.

$\mathrm{O}$ caminho preferencial gerado evoluiu devido à concentração de fluxo de águas pluviais, que escavaram o solo até interceptar o nível d'água, agravando o processo erosivo. Atualmente, trata-se de área ambientalmente

\section{Processos geológicos}

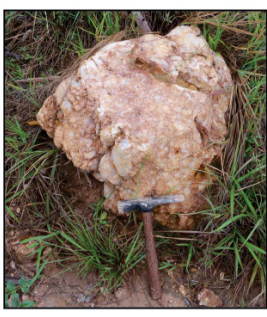

Bloco rolado

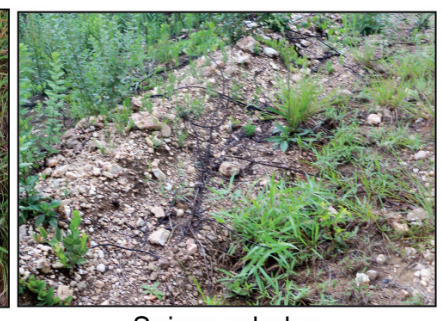

Seixos rolados
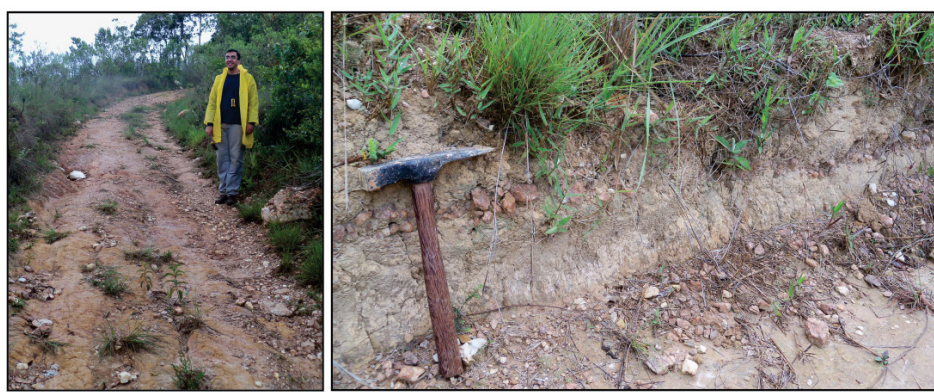

Erosão hídrica linear

Figura 9. Registro de processos erosivos e rolamento de blocos na Unidade B.
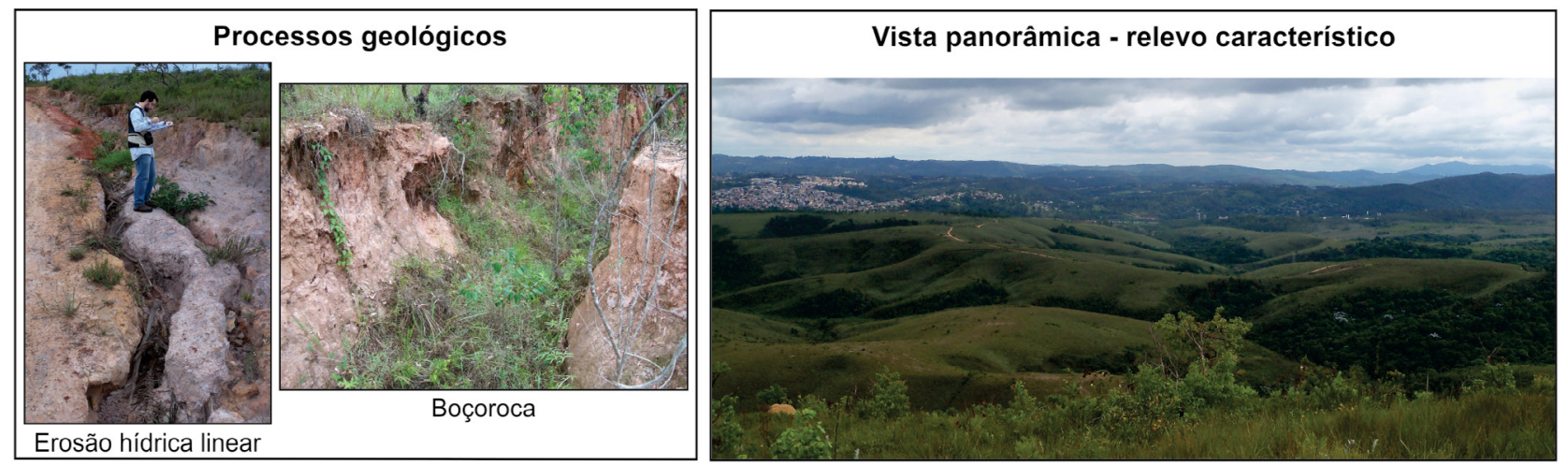

Figura 10. Registro de processos erosivos em estágio avançado na Unidade C. 
degradada (passivo ambiental), cujo processo erosivo, aparentemente, não está mais ativo e necessita de ações corretivas para recuperação.

\section{Subunidade C1: Cabeceiras de drenagem}

Essa subunidade se diferencia da anterior por apresentar terreno com predomínio de declividade média para movimentos de massa, encostas côncavas, perfil de solo menos desenvolvido, associado a áreas de cabeceiras de drenagens, que podem estar cobertas por vegetação densa ou rasteira.

Devido às características de evolução das vertentes, com erosão remontante e escorregamento (Figura 12), a subunidade é considerada de alta suscetibilidade aos processos erosivos e de moderada suscetibilidade aos processos de movimentação gravitacional de massa.
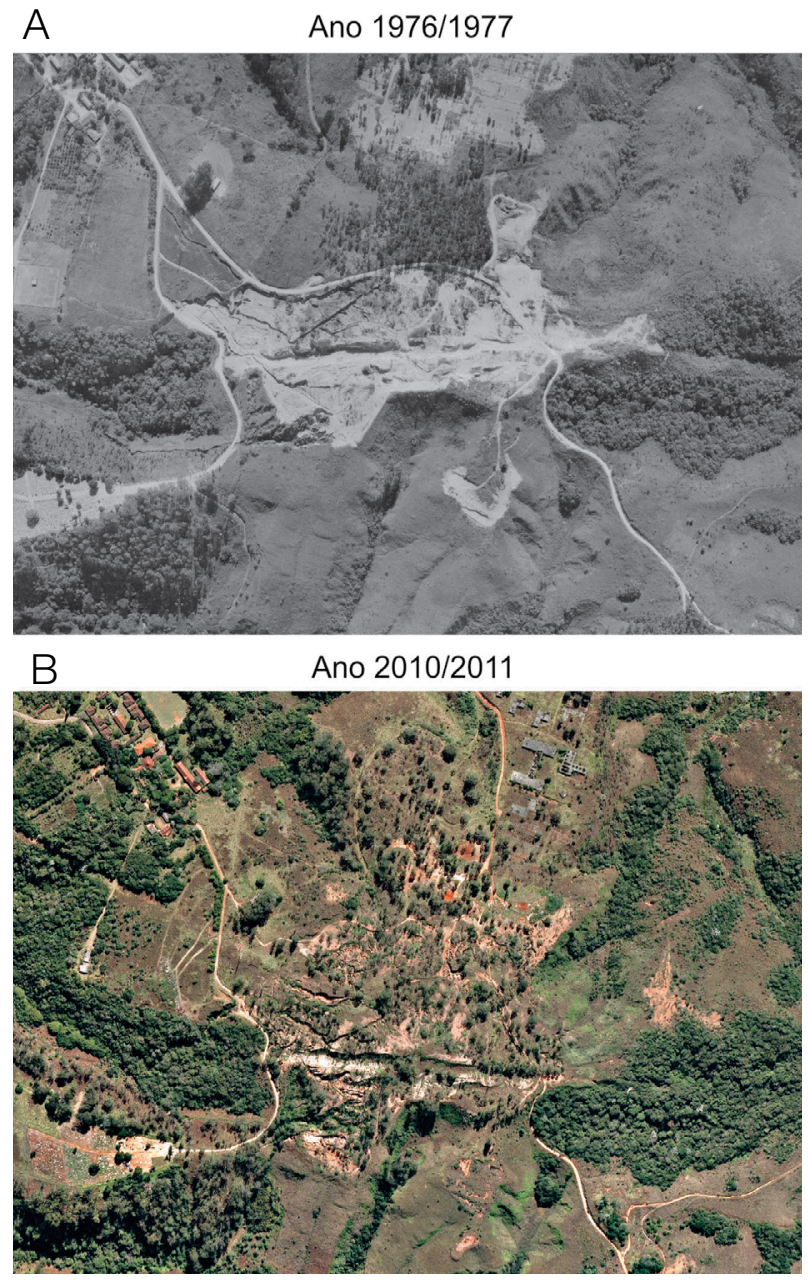

Figura 11. (A) Localização da movimentação de solo na década de 1970; (B) Llocalização da boçoroca em ortofoto dos anos de 2010 e /2011.
Na unidade não foram identificados condicionantes antrópicos que pudessem deflagrar os processos geológicos mencionados, entretanto, recomenda-se a preservação da vegetação nativa e a não intervenção nessas áreas, visto que possuem elevado potencial de formação de boçorocas.

\section{Unidade D: Rampas de colúvio}

A unidade é caracterizada por depósitos coluvionares, em terreno de baixa a média declividade para processos erosivos, com encosta convexa, baixa densidade textural, solo heterogêneo e inconsolidado com níveis de seixos.

Em relação ao uso do solo, foi observado o predomínio de vegetação rasteira e de solo exposto. A unidade apresenta condicionantes antrópicos, que nesse caso se caracterizam pela execução de taludes de corte inadequados, tanto na área da pista de pouso quanto nas estradas.

Observou-se em um dos pontos de campo, na faixa de rodagem de uma das estradas, a confluência das linhas de seixos com o corte realizado para implantação da via, que deflagrou processo acelerado de erosão (sulcos e ravinas) a jusante (Figura 13). Esses indícios, aliados às características do terreno, permitem o enquadramento da unidade como de alta suscetibilidade aos processos erosivos.

Quanto aos processos de movimentação gravitacional de massa, a unidade apresenta alta suscetibilidade devido às características do depósito, contudo, considerando os parâmetros adotados no estudo, a unidade foi classificada como de baixa suscetibilidade.

\section{Unidade E: Planícies aluvionares}

A unidade é representada pela planície aluvionar do Rio Juqueri e pelo fundo de vale de uma das drenagens. É caracterizada pela declividade baixa, amplitude pequena, alta taxa de permeabilidade, baixa coesão e alta espessura de material

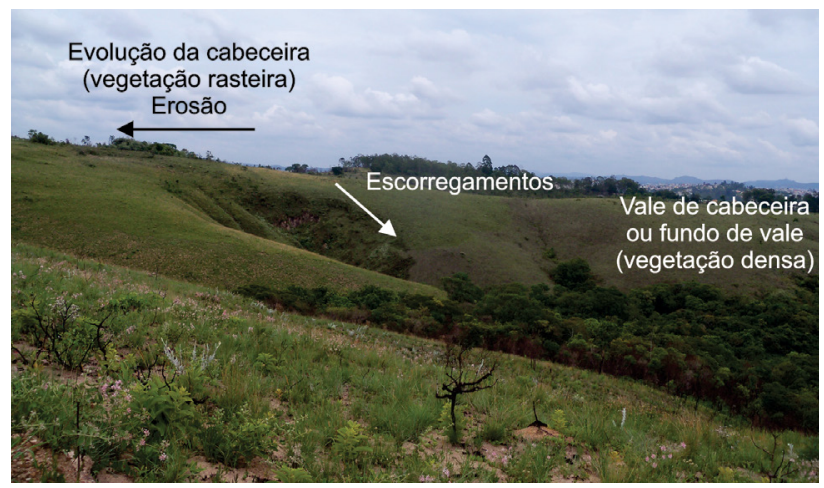

Figura 12. Evolução das cabeceiras de drenagem em anfiteatro, evidenciando os processos envolvidos e a diferença de cobertura vegetal. 
inconsolidado. Quanto ao uso do solo, a área é ocupada, em uma de suas margens, por vegetação rasteira e esparsa do PEJ, e, na outra, pela Favela Pretória.

Nos levantamentos realizados, observou-se que o rio está assoreado (Figura 14); segundo entrevista realizada, a ocorrência de enchentes tem se tornado mais frequente com a degradação do rio, o que reforça a hipótese de que as condições antrópicas influenciam na suscetibilidade da unidade.

Com moderada suscetibilidade aos processos erosivos e baixa suscetibilidade aos movimentos de massa, deve ainda ser considerada a possibilidade de ocorrência de processos de solapamentos de margem (rupturas dos taludes às margens do curso d'água devido à erosão após evento enchente ou inundação).

\section{Unidade F: Depósito de tálus em sopé de encosta}

A unidade se caracteriza por depósito de tálus (Figura 15), com terrenos acidentados de declividade alta, em torno dos $30 \%$, podendo alcançar pontualmente $45 \%$, e encostas convexas com distribuição simétrica de acordo com a Unidade A.
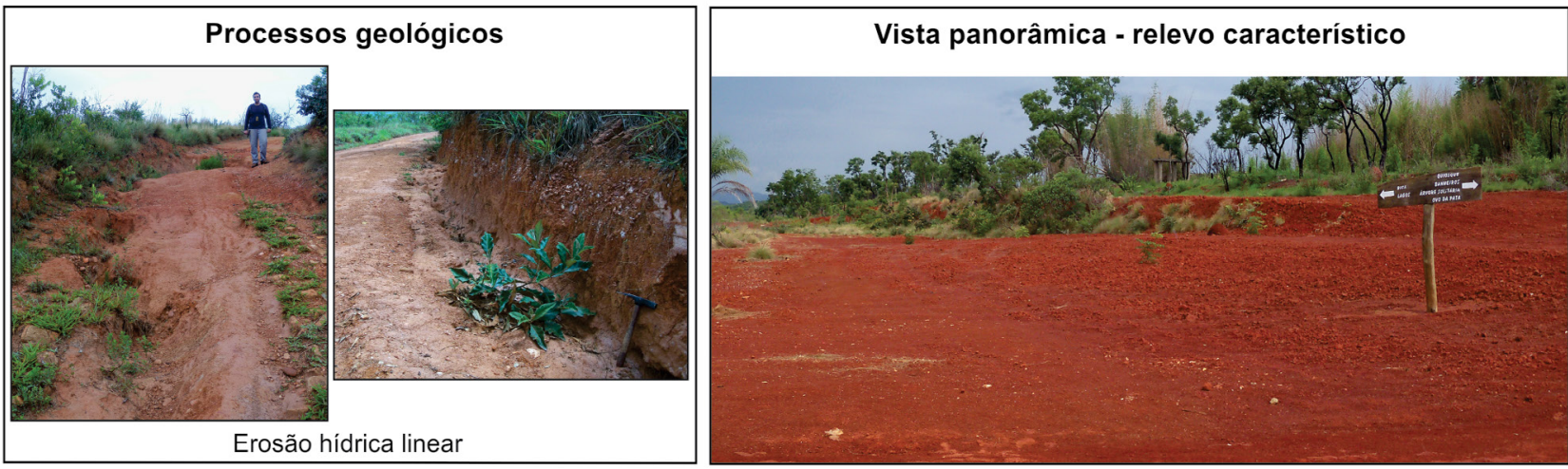

Figura 13. Registro de processos erosivos e relevo característico da Unidade D.
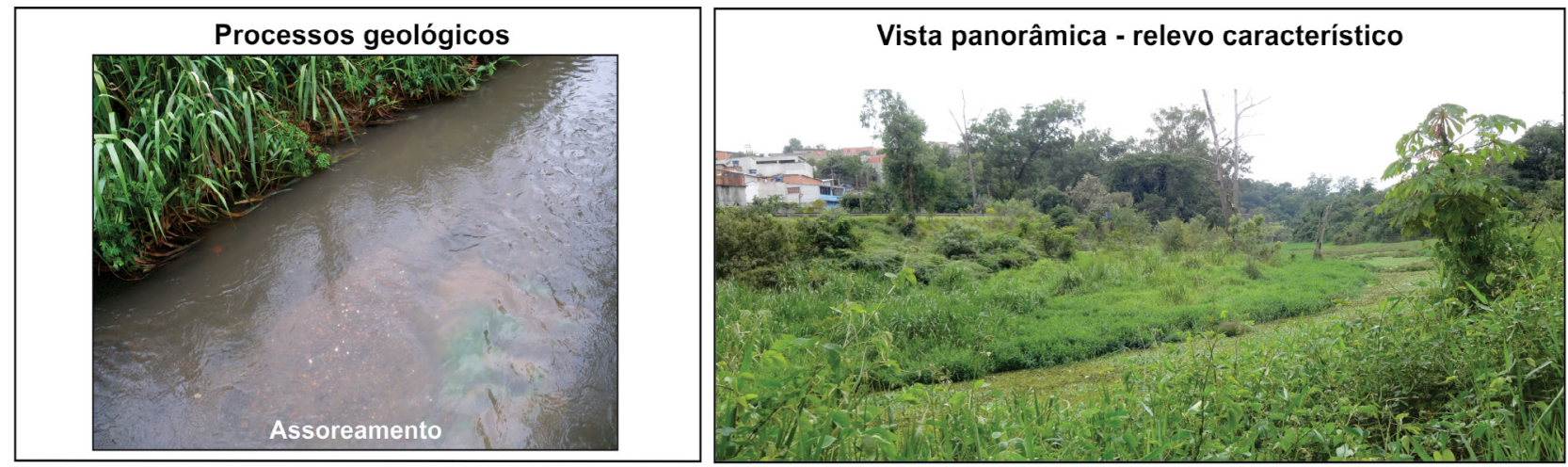

Figura 14. Registro de assoreamento no leito do afluente do Rio Juqueriy e relevo característico da Unidade E.
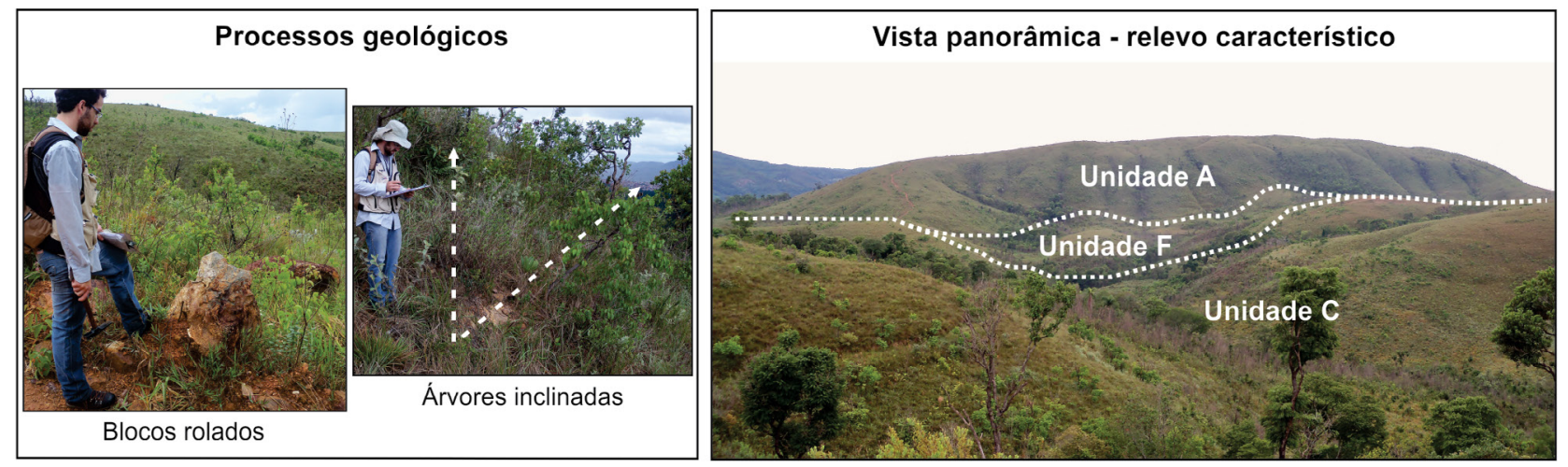

Figura 15. Registro de rolamento de blocos e rastejo, e relevo característico da Unidade F. 
A trilha é considerada um deflagrador antrópico, uma vez que a exposição do solo gera um caminho preferencial para o escoamento superficial, não sendo identificados sulcos e ravinas fora dos limites da trilha.

Em relação aos processos, a unidade foi classificada como de moderada suscetibilidade aos processos erosivos e moderada suscetibilidade aos processos de movimentos de massa, devido à composição heterogênea do depósito, à declividade acentuada e aos registros de processos erosivos e de rolamento de blocos, sendo observado predomínio dos processos gravitacionais sobre os erosivos.

Foi registrada a ocorrência de sulcos durante toda a trilha para subida e descida do Morro Grande, além de matacões disseminados por toda a unidade (Figura 13).

Devido às evidências identificadas no trabalho de campo e às características de instabilidade do depósito, a unidade deve ser considerada suscetível, também, aos processos de rastejo.

\section{CONCLUSÕES E RECOMENDAÇÕES}

O método adotado para a avaliação de suscetibilidade categorizou as unidades de forma qualitativa, sendo, para processos erosivos, as Unidades A, B, C, E e F, e a Subunidade $\mathrm{C} 1$ consideradas como de moderada possibilidade de ocorrência; a unidade D foi reconhecida como de alta suscetibilidade. Para processos de movimentos gravitacionais de massa, permitiu a classificação das Unidades B, C, D e E como de baixa suscetibilidade, as Unidades $\mathrm{A}, \mathrm{F}$ e a Subunidade $\mathrm{C} 1$ foram reconhecidas como de moderada suscetibilidade.

Cabe salientar que a classificação reflete a homogeneidade das unidades, porém se devem destacar a influência e a potencialização, pontual, que o uso do solo pode ter sobre a deflagração dos processos. Sendo assim, deve-se ressaltar a importância de a avaliação ser complementada com as informações de campo e a interpretação de quem executa a análise.

Verificou-se que $95 \%$ da área do parque possuem moderada predisposição aos processos erosivos e que $5 \%$ possuem alta suscetibilidade. Além disso, foram identificados dois setores críticos, sendo um deles enquadrado em alta suscetibilidade e outro mantido como setor crítico. Quando considerados os processos de movimentação gravitacional de massa, a área se distribui com baixa (88\%) e alta (12\%) suscetibilidade.

O setor crítico é caracterizado por processos erosivos acentuados, ao nordeste da área do parque, onde um trecho da estrada é paralelo à direção da foliação. A criticidade do trecho está associada ao comportamento distinto que cada litologia possui, uma vez que o filito é composto por bandamento composicional de camadas arenosas e pelíticas.
Nas porções central e oeste do parque, a maioria das estradas possui orientação N-S e NW-SE, que são perpendiculares a oblíquas à direção da foliação (E-W), associadas à declividade predominantemente baixa. Nesses casos são observados sulcos por concentração de fluxo hídrico nas laterais das estradas.

Ao leste, além de estradas com orientação N-S e NW-SE, há dois setores, com extensão aproximada de $1,5 \mathrm{~km}$, que coincidem com a orientação NE-SW da foliação nessa área. Essa combinação pode causar processos erosivos acentuados.

Aponta-se, ainda, a necessidade de recuperação da área degradada pela boçoroca, assim como recomenda-se o controle dos processos deflagrados pelas estradas e trilhas. Para as estradas, é necessária a adoção de medidas mitigadoras, como a instalação de equipamentos de drenagem e a estabilização dos taludes. Nas trilhas devem ser priorizadas medidas para controlar o fluxo de escoamento superficial, como a instalação de dissipadores de energia.

Com os resultados obtidos espera-se que esta pesquisa possa contribuir fornecendo subsídios para o desenvolvimento de instrumentos de gestão ambiental para a área de estudo.

\section{AGRADECIMENTOS}

Agradecemos à Empresa Paulista de Planejamento Metropolitano (EMPLASA) pela sessão sem ônus das fotografias aéreas utilizadas nesta pesquisa. Reconhecemos também a contribuição da gestão do PEJ no apoio aos trabalhos de campo.

\section{REFERÊNCIAS}

Ab' Saber, A. O. (1978). Reservatório do Juquerí na área de Mairiporã: estudos básicos para defesa ambiental e ordenação de espaços envolventes. Geografia e Planejamento, 32, 1-28.

Almeida, F. F. M. (1964). Fundamentos geológicos do relevo paulista. Boletim Instituto Geográfico e Geológico, 41, 169-263.

Almeida, F. F. M., Amaral, G., Cordani, U., Kawashita, K. (1973). The precambrian evolution of South American cratonic margin South of Amazon River. In: Nairn, Stelli (Eds.), The Oceans Basins and Margins (411-446). New York: Plenum.

Amorim, D. G. A. (2012). Caracterização geológicogeotécnica aplicada a gestão de risco no gasoduto Gasbol, trecho Ipeúna/SP - Itirapina/SP. Monografia (Graduação em Geologia). Rio Claro: Instituto de Geociências e Ciências Exatas - UNESP. 
Augusto Filho, O. (1992). Caracterização geológicogeotécnica voltada à estabilização de encostas: uma proposta metodológica. Conferência Brasileira sobre Estabilidade de Encostas, 1, 721-733. Rio de Janeiro: ABMS/ABGE.

Baitello, J. B., Aguiar, O. T., Pastore, J. A., Arzolla, F. A. R. D. P. (2013). Parque Estadual do Juquery: Refúgio de Cerrado no Domínio Atlântico. Instituto Florestal, 50, 1-46.

Bergmann, M. (1988). Caracterização estratigráfica e estrutural da sequência Vulcano sedimentar do grupo São Roque - Região de Pirapora do Bom Jesus - Estado de São Paulo. Dissertação (Mestrado). São Paulo: Instituto de Geociências - USP.

Campos Neto, M. C., Figueiredo, M. C. H. (1995). The Rio Doce Orogeny, Southeastern Brazil. Journal of South American Earth Sciences, 8(2), 143-162.

Cerri, L. E. S., Zaine, J. E., Paula, J. P. L. (2006). Curso: geologia aplicada ao patrulhamento de rede da COMGÁS. Material didático. São Paulo.

Cordani, U. G., Delhal, J., Ledent, O. (1973). Orogenèse superposées dans le Précambrien du Brésil Sud-Oriental (États de Rio de Janeiro et de Minas Gerais). Revista Brasileira de Geociências, 3(1), 1-22.

Dantas, A. S. L. (1990). Geologia da faixa São Roque e intrusivas associadas na região entre São Paulo e Mairiporã, norte de São Paulo - SP. Dissertação (Mestrado). São Paulo: Instituto de Geociências - USP.

Departamento de Água e Energia Elétrica - DAEE. (1990). Controle de erosão: bases conceituais e técnicas, diretrizes para planejamento urbano e regional; orientação para o controle de boçorocas urbanas. 2. ed. São Paulo: DAEE/IPT.

Departamento Nacional da Produção Mineral e Companhia de Pesquisa de Recursos Minerais - DNPM/CPRM. (1991). Projeto Integração Geológica da Região Metropolitana de São Paulo. São Paulo: DNPM/CPRM. 65p. 28 mapas.

Empresa Brasileira de Pesquisa Agropecuária - EMBRAPA. (2006). Sistema brasileiro de classificação de solos. 2. ed. Rio de Janeiro: Embrapa-SPI.

Empresa Paulista de Planejamento Metropolitano S.A. EMPLASA. (1977). Fotografias aéreas. Escala 1:8.000.

Empresa Paulista de Planejamento Metropolitano S.A. EMPLASA. (1979). Carta Geológica da Região Metropolitana de São Paulo. Escala 1:50.000. Folha 34. São Paulo.
Empresa Paulista de Planejamento Metropolitano S.A. EMPLASA. (1980). Folha Topográfica Franco da Rocha (SF-23-Y-C-III-4-NO-C), Bairro dos Valos (SF-23-Y-C-III4-NO-D), Caieiras (SF-23-Y-C-III-4-NO-E) e Vila Machado (SF-23-Y-C-III-4-NO-F). Escala 1:10.000. São Paulo.

Empresa Paulista de Planejamento Metropolitano S.A. EMPLASA. (2011). Fotografias Aéreas, Projeto Mapeia São Paulo. Resolução espacial: 0,45 metros. São Paulo.

Ferrari, A. A. P. (2005). Viabilidade da utilização de silte compactado como material de impermeabilização em aterros de resíduos. Dissertação (Mestrado). São Paulo: Escola Politécnica da USP - USP.

Figueiredo, M. C. H., Bergmann, M., Penalva, R., Tassinari, C. C. G. (1982). Ocorrência de "Pillow Lavas" no Grupo São Roque, Estado de São Paulo. Ciências da Terra, 2, 6-8.

Fundação de Apoio à Universidade de São Paulo - FUSP. (2009). Plano da Bacia Hidrográfica do Alto Tietê. Relatório Final, v.1/4, 201p. São Paulo.

Hackspacher, P. C., Dantas, E. L., Spoladore, A., Felter, A. H., Oliveira, M. A. F. (2000). Evidence of Neoproterozoic Backarc Basin Development in the Central Ribeira Belt, Southeastern Brazil: New Geochronological and Gechemical Constraints from the São Roque - Açungui Groups. Revista Brasileira de Geociências, 30, 110-114.

Hackspacher, P. C., Godoy, A. M., Oliveira, M. A. F. (1993). Evolução Crustal do Bloco São Roque, na Região Sudeste do Estado de São Paulo. Revista Brasileira de Geociências, 23(3), 260-264.

Hasui, Y., Carneiro, C. D. R. (1980). Origem e evolução da Bacia de São Paulo. Mesa-Redonda: aspectos geológicos e geotécnicos da bacia sedimentar de São Paulo, p. 47-52. São Paulo: ABGE/SBG.

Hasui, Y., Oliveira, M. A. F. (1984). A província mantiqueira: setor central. In: Almeida e Hasui (Eds.). O precambriano do Brasil. São Paulo: Edgard Blucher. 344 p.

Heilbron, M., Pedrosa-Soares, A. C., Silva, L. C., Campos Neto, M. C., Trouw, R. A. J. (2004). Província Mantiqueira. In: Mantesso-Neto, V., Bartorelli, A., Carneiro, C.D.R., BritoNeves, B.B. (Eds.). Geologia do Continente Sul-Americano (1-13). Rio de Janeiro: Beca.

Infanti Junior, N., Fornasari Filho, N. (1998). Processos de dinâmica superficial. In: A. M. S. Oliveira, S. N. A. Brito (Eds.). Geologia de engenharia, 1 (283-300). São Paulo: ABGE. 
Instituto Agronômico - IAC. (2014). Mapa de Solos do Estado de São Paulo. Acesso em: 27 de janeiro de 2015, $<$ http://www.iac.sp.gov.br/solossp/>.

Instituto de Pesquisas Tecnológicas do Estado de São Paulo IPT. (1981). Mapa Geomorfológico do Estado de São Paulo. PRÓ MINÉRIO/PROMOCET. v. 1, 94p.

Instituto de Pesquisas Tecnológicas do Estado de São Paulo - IPT. (2010). Diagnóstico dos processos erosivos e de assoreamento nas Microbacias Itaim, Tapera Grande, Criciúma, Tanque Velho/Abreus e Manguinho, da bacia hidrográfica do rio Juqueri (Relatório Técnico, 119616205). São Paulo.

Instituto de Pesquisas Tecnológicas do Estado de São Paulo - IPT. (2014). Cartas de suscetibilidade a movimentos gravitacionais de massa e inundações - 1:25.000. São Paulo: IPT. Acesso em: 30 de novembro de 2016, <http://rigeo. cprm.gov.br/xmlui/bitstream/handle/doc/16588/NTCarta Suscetibilidade.pdf? sequence $=1>$.

Juliani C., Beljavskis P. (1995). Revisão da litoestratigrafia da faixa São Roque/Serra do Itaberaba (SP). Revista do Instituto Geológico, 16(1/2), 33-58.

Juliani, C., Beljavskis, P., Schorscher, H. D. (1986). Petrogênese do vulcanismo e aspectos metalogenéticos associados: Grupo Serra do Itaberaba na região de São Roque - SP. Congresso Brasileiro de Geologia, 34, 730-747. Anais... Goiânia: SBG. Juliani C., Hackspacher P. C., Dantas E. L., Felter, A. H. (2000). The Mesoproterozoic volcano-sedimentary Serra do Itaberaba Group of the central Ribeira Belt, São Paulo State, Brazil: implications for the age of the overlying São Roque Group. Revista Brasileira de Geociências, 30(1), 82-86.

Luz, R. A. (2010). Geomorfologia da Planície Fluvial do Rio Pinheiros entre os Bairros de Pinheiros, Butantã e Cidade Jardim, São Paulo (SP). Dissertação (Mestrado). São Paulo: Departamento de Geografia - USP.
Martins, P. T. A. (2012). Carta de sensibilidade ambiental para derramamentos de óleo em rodovias: proposta aplicada a Estrada dos Tamoios (SP-099). Tese (Doutorado). 171p. Rio Claro: Instituto de Geociências e Ciências Exatas - UNESP.

Oliveira, J. B., Camargo, M. N., Rossi, M., Calderano Filho, B. (1999). Mapa pedológico do Estado de São Paulo. Campinas: IAC. Escala 1:500.000. Acompanha legenda expandida.

Rodrigues, F. H., Coelho, J. M., Santos, F. S. M., Amaral, A. M. C., Zaine, J. E. (2014). Avaliação da possibilidade de erosão natural e induzida na Bacia Hidrográfica do Ribeirão das Pedras, Quirinópolis (GO). Geociências, 33(2), 339-359.

Rodriguez, S. K. (1998). Geologia Urbana da Região Metropolitana de São Paulo. Tese (Doutorado). 171p. São Paulo: Instituto de Geociências - USP.

Ross, J., Moroz, I. C. (1997). Mapa geomorfológico do Estado de São Paulo: Escala 1:500.000. São Paulo: Laboratório de Geomorfologia, Departamento de Geografia - FFLCH USP/Laboratório de Cartografia Geotécnica - Geologia Aplicada - IPT/FAPESP.

Souza, L. A., Sobreira, F. G. (2014). Guia para elaboração de cartas geotécnicas de aptidão à urbanização frente aos desastres naturais. Ouro Preto: UFOP; Brasília: MCidades. Acesso em: 30 de novembro de 2016, <http://www.abge.org.br/ uploads/imgfck/file/GUIA_APTIDAO_A_URBANIZACAO_ SOUZA_E_SOBREIRA_2014.pdf $>$.

Takiya, H. (1997). Estudo da sedimentação neogênicoquaternária no Município de São Paulo: caracterização dos depósitos e suas implicações na geologia urbana. Tese (Doutorado). 152p. São Paulo: Instituto de Geociências-USP.

Zuquette, L. V., Gandolfi, N. (2004). Cartografia geotécnica. São Paulo: Oficina de Textos. 